\title{
Performance of heat pumps using pure and mixed refrigerants with maldistribution effects in plate heat exchanger evaporators
}

Mancini, Roberta; Zühlsdorf, Benjamin; Aute, Vikrant; Markussen, Wiebke Brix; Elmegaard, Brian

Published in:

International Journal of Refrigeration

Link to article, DOI:

10.1016/j.jirefrig.2019.05.023

Publication date:

2019

Document Version

Peer reviewed version

Link back to DTU Orbit

Citation (APA):

Mancini, R., Zühlsdorf, B., Aute, V., Markussen, W. B., \& Elmegaard, B. (2019). Performance of heat pumps using pure and mixed refrigerants with maldistribution effects in plate heat exchanger evaporators. International Journal of Refrigeration, 104, 390-403. https://doi.org/10.1016/j.ijrefrig.2019.05.023

\section{General rights}

Copyright and moral rights for the publications made accessible in the public portal are retained by the authors and/or other copyright owners and it is a condition of accessing publications that users recognise and abide by the legal requirements associated with these rights.

- Users may download and print one copy of any publication from the public portal for the purpose of private study or research.

- You may not further distribute the material or use it for any profit-making activity or commercial gain

- You may freely distribute the URL identifying the publication in the public portal 


\title{
Performance of heat pumps using pure and mixed refrigerants with maldistribution effects in plate heat exchanger evaporators
}

\author{
Roberta Mancini ${ }^{\mathrm{a}, *}$, Benjamin Zühlsdorf ${ }^{\mathrm{a}}$, Vikrant Aute ${ }^{\mathrm{b}}$, Wiebke Brix Markussen ${ }^{\mathrm{a}}$, Brian Elmegaard ${ }^{\mathrm{a}}$ \\ ${ }^{a}$ Technical University of Denmark, Department of Mechanical Engineering, Nils Koppels Allé, Building 403, 2800 Kongens Lyngby, Denmark \\ ${ }^{b}$ University of Maryland, Department of Mechanical Engineering, 4164 Glenn L. Martin Hall, College Park, MD 20742, US
}

\begin{abstract}
This paper presents a combined plate heat exchanger (PHE) - heat pump simulation framework for the evaluation of flow maldistribution in PHE evaporators and its effect on the cycle thermodynamic and economic performance. A case study of heat pump integration for waste heat recovery purposes in data centres was chosen to demonstrate the utilization of the simulation tool. The analyses were made for the pure fluids butane and propane, and for the zeotropic mixtures propylene/butane at $(0.5,0.5)$ mass composition and $\mathrm{CO}_{2} /$ dimethyl ether (DME) $(0.2,0.8)$ as refrigerants. Both liquid/vapour maldistribution and the effect of end plates were considered in the heat exchanger models. Results show that butane is most sensitive to maldistribution, with a maximum Coefficient of Performance (COP) reduction of $5.9 \%$, while propane experiences the lowest reduction of $2.5 \%$. The different sensitivity of the working fluids to maldistribution was found to be related to the evaporator design, refrigerant pressure drop, and fluid properties. Last, the results of the economic analysis show that a higher specific cost of heat is obtained when considering maldistribution effects.
\end{abstract}

Keywords: plate heat exchanger, liquid-vapour maldistribution, end plates, pressure drop, zeotropic mixtures, economic analysis

\section{Introduction}

Flow maldistribution implies a degradation in heat transfer performance for heat exchangers (HEXs) with multiple parallel channels. Mueller \& Chiou (1988) published a work defining maldistribution within the context of HEX design, namely as non-uniform mass flow distribution entailing a degradation of heat transfer between the working fluids. Three main causes were identified, i.e. entry problems due to improper nozzle design, self-induced maldistribution by fluid flow characteristics, e.g. viscous or two-phase flow, and fouling and corrosion effects.

Plate heat exchangers (PHEs) are one kind of multi-channel HEX, which is used extensively in a number of sectors. By stacking thin corrugated plates together, co- or counter-current flow channels are formed, and high heat transfer coefficients are achieved in a compact design.

Maldistribution in PHEs can be related to three main effects: (i)uneven channel-to-channel mass flow rate distribution, (ii) uneven in-channel mass flow rate distribution, and (iii) effect of end plates, i.e. the different heat transfer area of the outer-most PHE channels causes a modification of the mass flow distribution.

Single-phase channel-to-channel maldistribution in PHEs has been described analytically (Bassiouny \& Martin, 1984a,b; Srihari \& Das, 2006; Srihari et al., 2005), numerically (Li \& Hrnjak, 2016) and experimentally (Bobbili et al., 2006; Li \& Hrnjak, 2018; Rao \& Das, 2004; Rao et al., 2005; Tereda et al., 2007). A higher PHE performance degradation was found to occur for smaller manifold port diameters, higher mass flow rates and a higher number of channels. The effect of end plates in single-phase flow was studied by Jin \& Hrnjak (2017b). They found that an overestimation of the overall heat transfer coefficient occurs by neglecting the effect of end plates, due to an

\footnotetext{
* Corresponding author

Email addresses: robman@mek.dtu.dk (Roberta Mancini), bezuhls@mek.dtu.dk (Benjamin Zühlsdorf), vikrant@umd.edu (Vikrant Aute), wb@mek.dtu.dk (Wiebke Brix Markussen), be@mek.dtu.dk (Brian Elmegaard)
} 
underestimation of the effective heat transfer area. Li \& Hrnjak (2018) developed a validated model for single-phase flow distribution in PHEs, showing that plates with higher length-to-width ratios are less affected by maldistribution.

Two-phase flow maldistribution in PHEs was addressed by a few studies. Jin \& Hrnjak (2017a) investigated the in-channel distribution of R245fa experimentally. Large non-uniformities of the refrigerant mass flow rate were observed, with the occurrence of dry-out zones. Channel-to-channel flow maldistribution is particularly relevant for PHE evaporators in vapour compression systems. Since the refrigerant inlet is in two-phase, a non-uniform mass flow rate distribution entails uneven liquid/vapour distribution. Vist \& Pettersen (2004) observed this phenomenon experimentally in a HEX manifold distributing saturated refrigerant mass flow into ten channels. They observed a monotonic decrease/increase of the inlet vapour phase with increasing distance from the inlet, for upward/downward flow, respectively. Madanan et al. (2018) investigated the two-phase flow distribution of an air/water mixture from a U-type manifold into six and eight parallel horizontal mini-channels. The vapour phase distribution resulted to be dependent on the flow regime. A monotonic decrease was observed in case of slug flow and six channels, while oscillations occurred for the experiments with eight channels and plug flow.

By taking the experimental results observed by Vist \& Pettersen (2004) into account, Jensen et al. (2015) imposed different linear profiles of vapour quality at the PHE evaporator inlet by means of a numerical model with R134a used as a refrigerant and two different plate geometries. Mancini et al. (2018a) extended the work by comparing the degradation of heat transfer performance due to this kind of uneven liquid/vapour maldistribution for pure fluids and zeotropic mixtures. The use of a zeotropic mixture was demonstrated to increase the thermodynamic performance of heat pumps with respect to pure fluids by reducing the irreversibility in the HEXs (Zühlsdorf et al., 2019, 2018a,b). Zühlsdorf et al. (2018a) further showed that the temperature glide match in the evaporator has a dominating effect compared to the condenser, which suggests that major attention should be given to the optimal design and operation of the evaporator.

Mancini et al. (2018a) showed that a mixture of propylene/butane at $0.5 / 0.5$ mass composition is only slightly affected by maldistribution effects. The refrigerant temperature distribution in the different channels was shown to remain unchanged for different rates of liquid/vapour non-uniformity at the inlet, resulting in no changes for the temperature glide match. The pure fluid butane is on the other hand subject to a degradation in total heat transfer of up to $11.2 \%$. The results were however limited to a particular case study (Zühlsdorf et al., 2018b), and the impact on the overall cycle performance was not estimated.

It is in fact of paramount importance to evaluate how the heat transfer degradation in evaporators affects the thermodynamic performance of the cycle. Previous works address the analysis of flow maldistribution effects in air conditioning systems (Kærn et al., 2011) and heat pumps (Gong et al., 2008; Mader et al., 2015) for fin-and-tube evaporators.

This paper presents a combined cycle and PHE simulation framework, which can be used in order to assess the impact on the Coefficient of Performance (COP) of heat pumps caused by end plates and liquid/vapour maldistribution at the inlet of PHE evaporators. The procedure is demonstrated by applying it to a relevant case study (Zühlsdorf et al., 2019), evaluating four different working fluids among pure and mixed refrigerants. The case study is also used as an explanatory example to estimate the impact on the system operating costs, thereby highlighting the importance of taking the heat transfer degradation in evaporators due to flow maldistribution into account when assessing the techno-economic feasibility of heat pump systems, as well as it allows comparing different refrigerants.

\section{Methods}

This section presents the procedure that was developed for evaluating the impact of maldistribution on the heat pump COP. The models were published in Mancini (2018), where the scripts utilized for the case study analysis can be accessed together with a detailed documentation. The numerical models were built and integrated in the Matlab simulation environment (Mathworks, 2017b).

\subsection{Integrated framework for coupled cycle-PHE analysis}

Fig.1 shows the schematic of the procedure developed in this study. The work addressed the estimation of the offdesign performance of both evaporator and cycle due to flow maldistribution. It was however coupled with preliminary cycle and HEX design. 


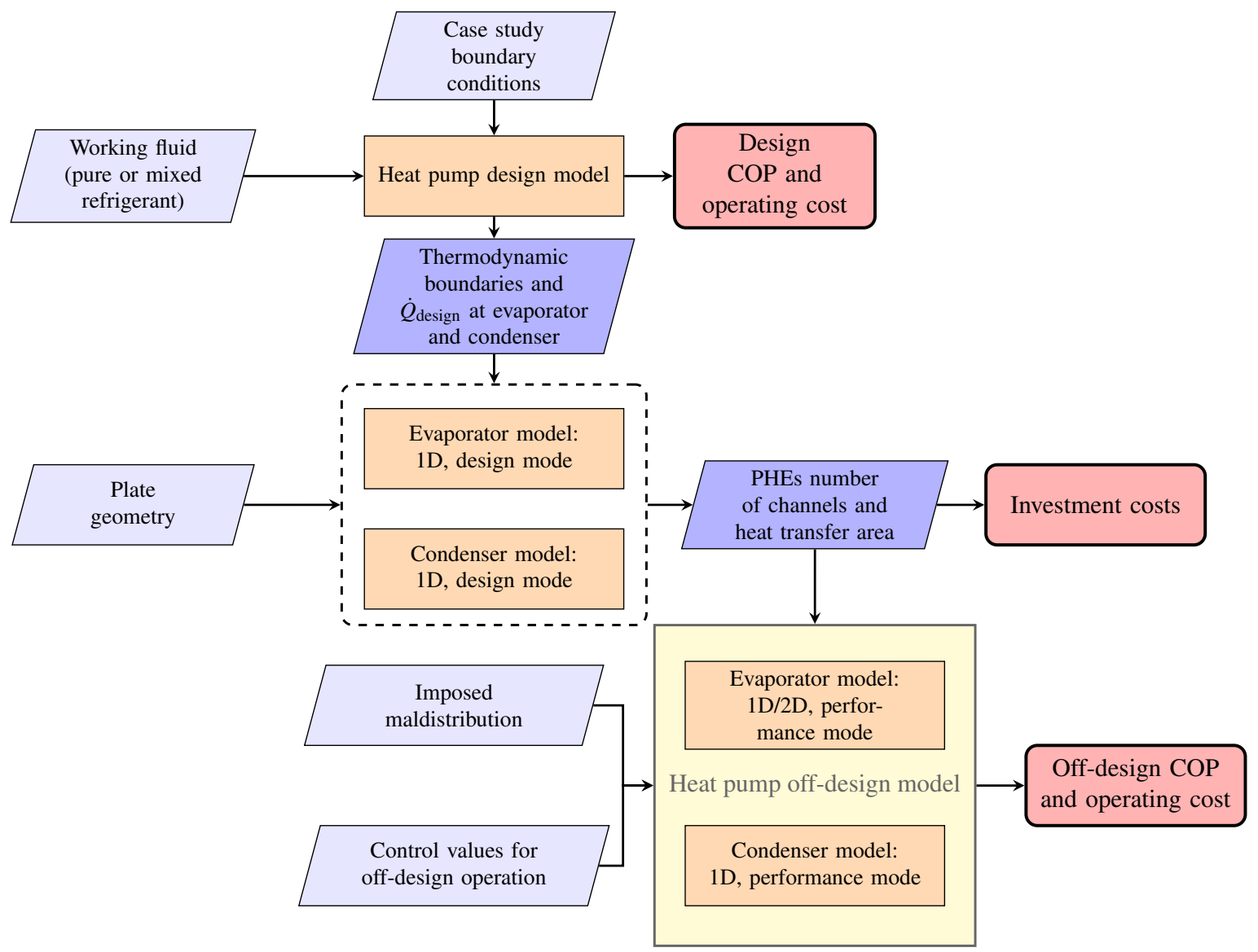

Figure 1: Work-flow of the overall procedure

First, the boundary conditions for the heat pump sizing and the working fluid were defined. The heat pump design model allowed estimating the $\mathrm{COP}$ and the operating cost at design conditions. The refrigerant design mass flow rate, together with the thermodynamic state of the refrigerant, heat source and heat sink at evaporator and condenser inlet and outlet were obtained as additional outputs and used in order to size the HEXs. The PHE evaporator and condenser models in design mode estimated the number of channels for a given plate geometry, thereby allowing the calculation of the total investment required for the heat pump. In order to evaluate the effect of maldistribution, a two-dimensional (2D) evaporator model was developed and integrated with a heat pump model, containing off-design calculations for the remaining components and the condenser model in performance mode, based on a one-dimensional (1D) discretization. The overall off-design analysis was carried out for different imposed liquid/vapour maldistribution rates, which allowed estimating the impact on the heat pump COP and operating cost. The off-design model was additionally implemented by using an evaporator model in 1D. The aim was to assess the difference between an ideal distribution of the mass flow rate (equal to using the 1D model) and the 2D model with a uniform quality distribution at the inlet, thereby quantifying the effect of end plates. This will be futher explained in subsection 2.4. The following subsections present in details the different submodels, base of the overall procedure. More focus is given to the PHE modelling, since the heat pump cycle modelling approach was based on the work by Zühlsdorf et al. (2019) with a more detailed characterization of the HEX components for both design and performance calculations.

\subsection{Heat pump design model}

The thermodynamic cycle was modelled in steady-state operation as a single-stage vapour compression heat pump with four components, as shown in Fig. 2. The design procedure was based on a fixed load at the evaporator or the condenser depending on the constraints of the specific case study. The design parameters were given by minimum 
pinch temperature differences in the HEXs, minimum superheat and fixed subcooling. The compressor was modelled by defining isentropic and motor efficiencies, while an isenthalpic operation of the expansion valve was assumed. The design model was developed for both pure and mixed refrigerants. The thermodynamic performance of the heat pump was evaluated by means of the COP, as expressed by Eq. (1).

$$
\mathrm{COP}=\frac{\dot{Q}_{\text {sink }}}{\dot{W}_{\text {comp }}}
$$

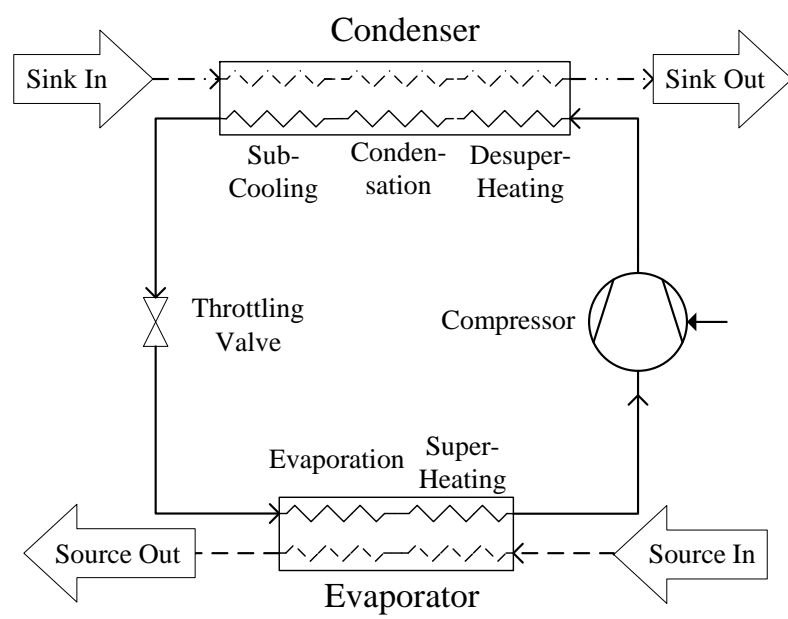

Figure 2: Schematic of the heat pump model

\subsection{Heat exchangers models}

The simulation framework comprises HEX models, which can be run in either design or performance mode, to respectively solve the design and performance problems. The design mode aims at calculating the physical size of the HEX for a given heat load, mass flow rates and inlet and outlet temperatures and pressures. The performance mode aims at estimating the heat transfer and pressure drop of an already sized HEX, thereby using the full HEX geometry, inlet thermodynamics, and mass flow rates as input and calculating heat flow rate, pressure drop and outlet temperatures and pressures (Shah \& Sekulic, 2002).

The models were based on an internal solver for the solution of heat transfer and fluid flow, presented in subsection 2.3.1. Different external solvers were employed for the solution of the design problem and of the performance problem, as described respectively in subsections 2.3.3 and 2.4. Note that the two performance solvers for evaporator and condenser were directly coupled with the equations for off-design operation of the heat pump.

The following assumptions were employed in all the models: (i) steady-state operating conditions, (ii) adiabatic end plates, i.e. no heat loss to the environment (iii) no longitudinal conduction through the plates, (iv) separated flow model for liquid and vapour phases, and (v) no pressure drop in the PHE manifolds. The manifold pressure drop can in some cases constitute a relevant contribution to the total pressure drop. It was however decided to neglect it since it is a term highly impacted by the real design of the HEX from specific manufacturers. Moreover, Li \& Hrnjak (2018) showed that manifold pressure drop decreases with decreasing number of channels and increasing length-to-width ratios of the plates, thereby becoming negligible compared to channel pressure drop for PHE channels number lower than 100 and typically manufactured length-to-width ratios.

\subsubsection{Solver for heat transfer and fluid flow}

The solver for heat transfer and fluid flow was implemented to solve the PHE model in performance mode, i.e. with the full geometry and inlet thermodynamics and mass flow rates specified as inputs. The solver iterated on wall temperatures and pressure drops of both fluids, i.e. refrigerant and secondary fluid, following a successive substitution approach, in order to estimate the total heat flow rate and pressure drops of both fluids. Based on a start guess of linear 
wall temperature profile and pressure drop distributed evenly in the control volumes (CVs) along the flow direction for both fluids, the mass, momentum, and energy conservation equations were solved iteratively for each CV. An alternate iteration approach, as suggested by Eldeeb et al. (2016), was implemented in order to accelerate the model convergence.

The evaporator model in performance mode was based on both $1 \mathrm{D}$ and 2D discretization approaches. The latter was used in order to describe maldistribution effects. The discretization schemes and iteration variables are shown in Fig. 3 (a) for the 1D case and (b) for the 2D case. A 1D discretization approach - similar to the one shown for the evaporator in Fig. 3(a) - was applied for the condenser model. In this last case, the mass flow of both fluids was assumed to distribute uniformly, thereby applying the discretization solely along the fluid flow direction with uniform steps of heat transfer area.

Table 1 reports the discretization details for the solvers. The convergence criterion was defined based on the $l^{2}$ norm of the relative residuals of the wall temperature and refrigerant and secondary fluid pressure drop. A higher number of CVs was applied in the condenser case as a result of the grid independence study. Fluid thermo-physical properties were estimated by means of REFPROP 10 (Lemmon et al., 2018) for the refrigerants and CoolProp (Bell et al., 2014) for water.

Table 1: Discretization and tolerances adopted for the PHE models

\begin{tabular}{lcccc}
\hline & \multicolumn{2}{c}{ Design models } & \multicolumn{2}{c}{ Performance models } \\
& Evaporator & Condenser & Evaporator & Condenser \\
\hline Type of discretization & $1 \mathrm{D}$ & $1 \mathrm{D}$ & $1 \mathrm{D} / 2 \mathrm{D}$ & $1 \mathrm{D}$ \\
Number of CVs & 50 & 110 & $50 / 50 \times\left(N_{\text {ch,ref }}+N_{\text {ch,hs }}\right)$ & 110 \\
Tolerance & $10^{-5}$ & $10^{-5}$ & $10^{-5}$ & $10^{-5}$ \\
\hline
\end{tabular}

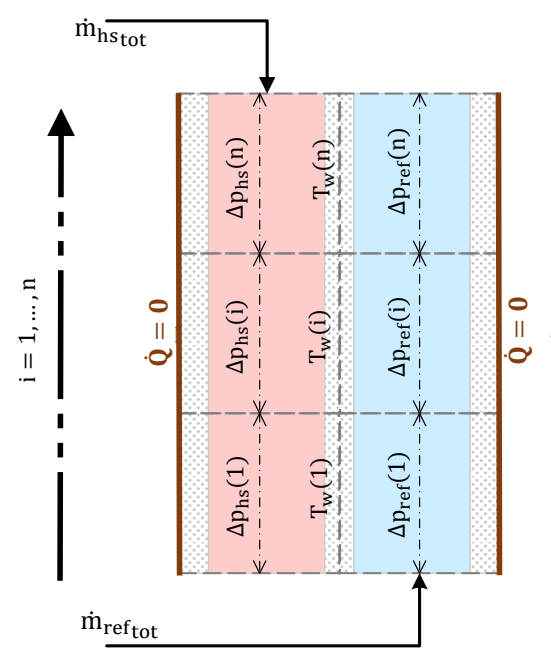

(a)

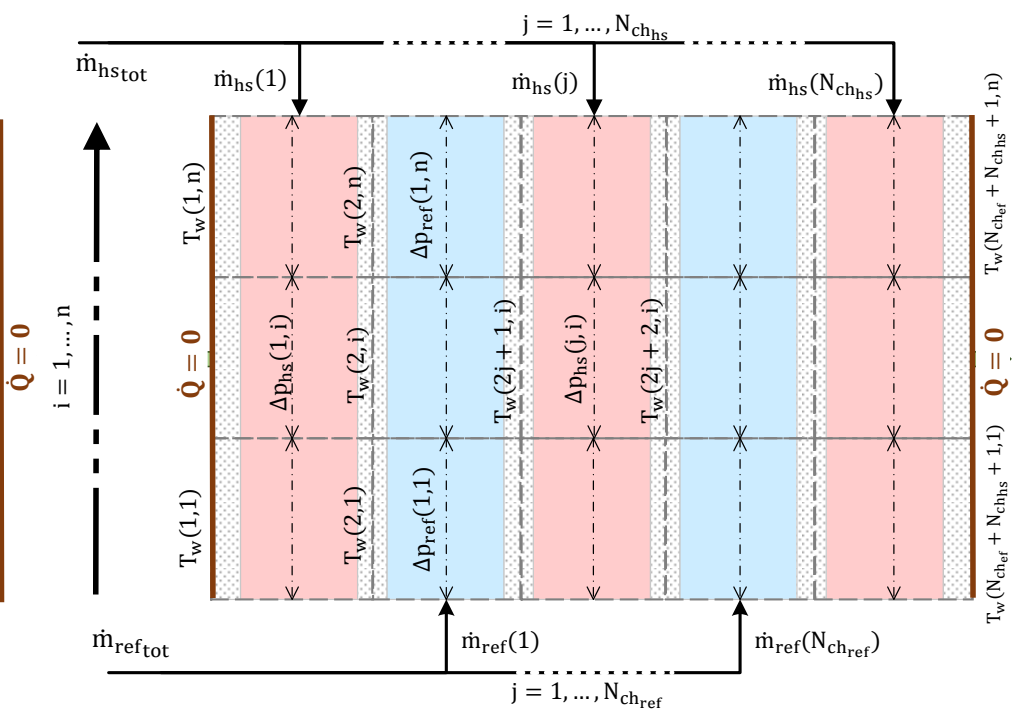

(b)

Figure 3: Discretization approaches for evaporator: 1D (a); 2D (b)

\subsubsection{Correlations for heat transfer coefficients and pressure drop}

Correlations were used for the computation of heat transfer coefficients, frictional pressure drop and void fraction for each control volume in both two-phase and single-phase flow.

The evaporation and condensation heat transfer coefficients for pure fluids were estimated by Amalfi et al. (2016) and Yan et al. (1999), respectively. The Silver (1947) and Bell \& Ghaly (1973) method was instead applied to 
account for mixture degradation of heat transfer during both evaporation and condensation. The method was initially developed for mixture condensation and was later extended to evaporation by Sardesai et al. (1982). For mixture condensation, the ideal heat transfer coefficient was computed using Yan et al. (1999), while Martin (1996) was used for the vapour phase correction term. For the evaporation heat transfer coefficient of mixtures, Mancini et al. (2018b) showed that small deviations on the total heat flow rate are obtained regardless of the combination of heat transfer correlations chosen for the method. Therefore, Amalfi et al. (2016) was applied for the two-phase convective contribution, Cooper (1984) was used for the ideal nucleate boiling contribution, Thome \& Shakir (1987) was used for estimating the mixture correction for the nucleate boiling term and Martin (1996) was applied for the single-phase vapour contribution.

The Lockhart \& Martinelli (1949) method was applied to evaluate two-phase evaporation frictional pressure drop. The method was applied as proposed by Palm \& Claesson (2006), i.e. Martin (1996) was used to estimate the singlephase frictional pressure drop and the correlation developed by Chisholm (1967) estimated the two-phase multiplier with a Chisholm parameter equal to 4.67. The Fanning friction factor correlation proposed by Yan et al. (1999) was instead used for condensation frictional pressure drop. Regarding pressure drop, no distinction was made between pure and mixed refrigerants and the same methods were applied for both evaporation and condensation.

Since no void fraction correlation is available in literature for PHEs, the widely used correlation presented by Smith (1969) was used to estimate the cross-sectional average density and the momentum density, which respectively are needed to compute the gravitational and acceleration contributions to pressure drop. The correlation was chosen since it was proven to well correlate data for two-phase upward annular flow (Godbole et al., 2011), which is a reasonable assumption in PHE evaporators (Vakili-Farahani et al., 2015).

A smooth transition was ensured between two-phase and single-phase in both superheated and subcooled regions for both evaporator and condenser, to avoid discontinuities. This was carried out by calculating the refrigerant heat transfer coefficient and frictional pressure drop by interpolating the two-phase and single-phase contributions at the interface. The smoothing was applied to the CVs with local vapour quality included in the intervals $[0,0.1]$ and $[0.9$, $1.0]$.

\subsubsection{Solver for the design problem}

The evaporator and condenser models in design mode were solved based on an external solver iterating on the total number of channels in order to meet a dimensioning thermal load for a given plate geometry, following the Newton-Raphson method. The work-flow of the implemented solver is shown in Fig. 4. The plate size (given by width $W$, length $L$ and thickness $t$ ) were defined together with the characteristic chevron-PHE corrugation height $b$, corrugation pitch $\Lambda$ and chevron angle $\beta$. The inlet states and the mass flow rates of both working fluids were also fixed. An initial guess of the total number of channels $N_{\mathrm{ch}}$ was provided to the solver for heat transfer and fluid flow. The solver estimated the total heat flow rate, and the first derivative with respect to $N_{\mathrm{ch}}$, subsequently used to update the guess value. The tolerance on the relative residual of the total heat flow rate was fixed to $10^{-3}$. The required heat transfer area was calculated as the output of the solver.

\subsection{Off-design conditions: Coupled cycle and PHE models in performance mode}

The off-design conditions were solved by creating an overall solver for the cycle, the PHE condenser and the PHE evaporator with and without liquid/vapour maldistribution. The solver was based on the fsolve algorithm (Mathworks, 2017a) coupled with the solver for heat transfer and fluid flow of condenser and evaporator and calculations for offdesign compressor performance. The solver for heat transfer and pressure drop of both evaporator and condenser was presented in Subsection 2.3.1. The compressor performance during off-design operation was evaluated by using the correlation presented in Granryd et al. (2009), relating the isentropic efficiency to the deviating pressure ratio. This correlation is valid for volumetric compressors with built-in volume ratios, which are typically used in many heat pump applications. A full description of all the governing equations for all the components can be found in the model documentation available in Mancini (2018).

In the off-design model without maldistribution effects, the unknowns were defined as the heat pump operating conditions, while for the off-design model with maldistribution effect the unknowns were given by the operating conditions and the mass flow rate distribution inside the evaporator. More specifically, the total mass flow rate of the refrigerant $\dot{m}_{\text {ref,tot }}$ and of the heat sink $\dot{m}_{\text {sink,tot }}$, the evaporation pressure $p_{\text {eva }}$ and condensation pressure $p_{\text {cond }}$ were 


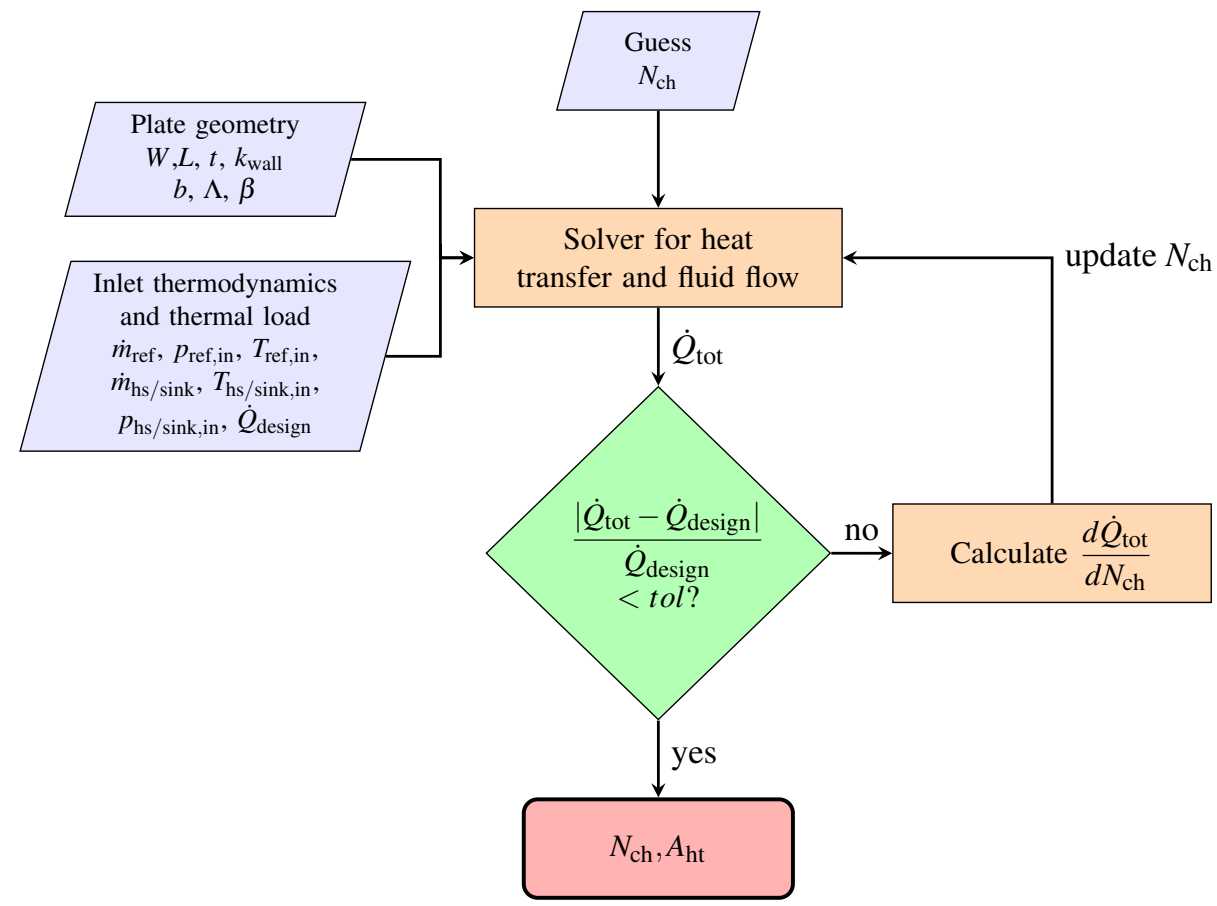

Figure 4: Work-flow of the solver for the design problem

chosen as the four variables describing the cycle operation. For the off-design model with maldistribution effects, where the evaporator was discretized based on a 2D approach, the vectors containing the mass flow rate distribution of the refrigerant and heat source in the different channels, namely $\dot{m}_{\text {ref }}$ and $\dot{m}_{\mathrm{hs}}$, constituted by $N_{\mathrm{ch}, \text { ref }}$ and $N_{\mathrm{ch}, \mathrm{hs}}$ elements each, were set as additional unknowns, together with the inlet vapour quality $x_{\text {ref,in }}$.

The equations implemented are reported in Table 2 for the off-design model without maldistribution effects. The four equations describe the operating strategy of the heat pump, thus dependent on the boundary conditions for the specific case study. In this case, the refrigerant superheat at the evaporator outlet, the suction volume flow rate at the compressor inlet, the refrigerant subcooling, and the sink outlet temperature were chosen as control values, thus fixed to the values at the design point.

Table 3 reports instead the additional equations needed for the off-design model with maldistribution effects, describing the mass flow rate distribution of refrigerant and heat source in the different PHE evaporator channels. Table 3 shows a total of $N_{\text {ch.ref }}+N_{\text {ch.hs }}+1$ governing equations, since the outlet pressure equalization equations for both refrigerant and heat source (reported in the second row) consisted of $N_{\mathrm{ch}, \text { ref }}-1$ and $N_{\mathrm{ch}, \mathrm{hs}}-1$ equations, respectively.

Table 2: Operating conditions equations for off-design operation

\begin{tabular}{cc}
\hline Evaporator & Condenser \\
$\bar{T}_{\text {ref,out }}-T_{\text {dew }}=\Delta T_{\text {SH }}$ & $\bar{T}_{\text {ref,out }}=T_{\text {sink,in }}+\Delta T_{\text {pinch,min }}$ \\
$\dot{m}_{\text {ref,tot }} \cdot \bar{\rho}_{\text {ref,out }}=\dot{V}_{\text {ref,out }}$ & $T_{\text {sink,out }}=T_{\text {sink,out-design }}$
\end{tabular}


Table 3: Evaporator flow distribution equations

\begin{tabular}{|c|c|}
\hline \multicolumn{2}{|c|}{ Mass conservation in manifold } \\
\hline Heat source & Refrigerant vapour \\
\hline$\sum_{j=1}^{N_{\mathrm{ch}, \mathrm{ref}}} \dot{m}_{\mathrm{ref}}^{(j)}=\dot{m}_{\mathrm{ref}, \mathrm{tot}} \quad \sum_{j=1}^{N_{\mathrm{ch}, \mathrm{hs}}} \dot{m}_{\mathrm{hs}}^{(j)}=\dot{m}_{\mathrm{hs}, \mathrm{tot}}$ & $\sum_{j=1}^{N_{\mathrm{ch}, \mathrm{ref}}} \dot{m}_{\mathrm{ref}}^{(j)} \cdot x_{\mathrm{ref}, \text { in }}^{(j)}=\dot{m}_{\mathrm{ref}, \text { tot }} \cdot x_{\mathrm{ref}, \text { in }}$ \\
\hline \multicolumn{2}{|c|}{ Outlet pressure equalization } \\
\hline Refrigerant & Heat source \\
\hline$\sum_{i=1}^{n} \Delta p_{\mathrm{ref}}^{(j, i)}=\sum_{i=1}^{n} \Delta p_{\mathrm{ref}}^{(j+1, i)}$ & $\sum_{i=1}^{n} \Delta p_{\mathrm{hs}}^{(j, i)}=\sum_{i=1}^{n} \Delta p_{\mathrm{hs}}^{(j+1, i)}$ \\
\hline$j=1, \ldots, N_{\mathrm{ch}, \mathrm{ref}}-1$ & $j=1, \ldots, N_{\mathrm{ch}, \mathrm{hs}}-1$ \\
\hline
\end{tabular}

As indicated in Fig. 1, the maldistribution rate was an input to the off-design model with maldistribution effects. A linear vapour quality variation was therefore imposed to the channels at the PHE inlet, similarly to Mancini et al. (2018a). The variation was calculated as function of a parameter $\Delta x$, representing the difference in vapour quality between the outer-most PHE refrigerant channels. The inlet quality at the $j$-th channel was thus estimated as function of the quality at the first channel, as expressed by Eq. (2).

$$
x_{\text {in }}^{(j)}=x_{\text {in }}^{(1)}+\frac{j-1}{N_{\text {ch,ref }-1}} \Delta x
$$

The parameter $\Delta x$ was varied between zero (for even distribution) and 0.25 by steps of 0.05 . An example of the imposed variation of vapour quality for a case of 11 refrigerant channels is shown in Fig. 5, where each colour represents a different maldistribution rate and therefore a different off-design operation point of both evaporator and heat pump.

The effect of end plates corresponded to the case of $\Delta x=0$. In this last case, an even distribution of the vapour quality was imposed at the inlet of the PHE channels. The mass flow distribution of both refrigerant and heat source is however non-uniform, since it is affected by the outer-most channels that are assumed perfectly adiabatic towards the outer environment. The difference between the $1 \mathrm{D}$ evaporator model and the $2 \mathrm{D}$ evaporator model with $\Delta x=0$ allowed quantifying this effect on both evaporator and heat pump performance.

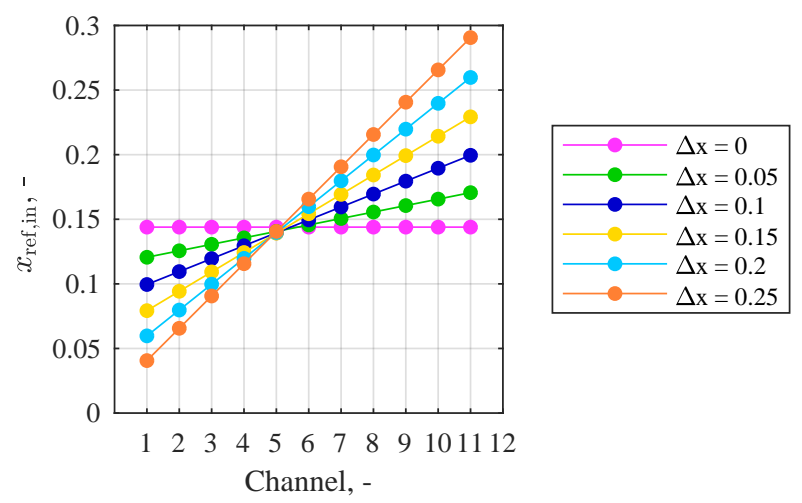

Figure 5: Imposed vapour quality maldistribution for a PHE with 11 refrigerant channels 


\subsection{Economic analysis}

The impact of maldistribution on the economic performance of the heat pump was evaluated using the integrated framework presented above. The degradation of COP in off-design conditions entails a drop of economic performance. By considering the economic boundary conditions case by case, the change in operating costs and revenue streams can be evaluated. The reader is referred to Zühlsdorf et al. (2019) for a comprehensive discussion about evaluating costs and revenues for heat pumps in different applications. A common indicator is given by the (levelized) specific cost of heat, calculated in $€ / M W h$ by Eq.(3). It is function of the different cash flow (CF) terms: the cost of electricity $\mathrm{CF}_{\mathrm{el}}$ and the income of supplying cold by cooling the heat source $\mathrm{CF}_{\mathrm{hs}}$. Moreover, it depends on the Total Capital Investment (TCI), Capital Recovery Factor (CRF) and the yearly production of heat, evaluated by multiplying the condenser load $\left(\dot{Q}_{\text {sink }}\right)$ by the yearly operating hours $(\mathrm{OH})$.

$$
c_{\mathrm{h}}=\frac{\mathrm{CF}_{\mathrm{el}}-\mathrm{CF}_{\mathrm{hs}}+\mathrm{TCI} \cdot \mathrm{CRF}}{\dot{Q}_{\text {sink }} \cdot \mathrm{OH}}
$$

\subsection{Case study}

The present section aims at introducing the case study chosen to demonstrate the utilization of the coupled cyclePHE analysis procedure. The case was previously published in Zühlsdorf et al. (2019), without considering detailed HEX design and maldistribution effects in evaporators. Subsection 2.6.1 presents the choice of the working fluids and the heat pump boundary conditions. Subsections 2.6.2 and 2.6.3 highlight the assumptions and criteria adopted for the cycle and PHEs design, respectively. Last, subsection 2.6.4 describes the economic boundary conditions.

\subsubsection{Working fluids and boundary conditions}

The case study aims at integrating heat pumps in data centre facilities for excess heat recovery purposes, for supplying heat to a district heating (DH) network. Zühlsdorf et al. (2019) carried out a screening of working fluids, including both pure and mixed refrigerants, aiming at maximizing the cycle COP. Table 4 reports four working fluids that were found among the most promising from both thermodynamic and economic standpoints, namely the two pure fluids butane and propane, and the two zeotropic mixtures propylene/butane and $\mathrm{CO}_{2} /$ dimethyl ether (DME) at $(0.5 / 0.5)$ and $(0.2 / 0.8)$ mass compositions, respectively. The heat pump design parameters and resulting operating pressures, suction volume flow rate, $\mathrm{COP}$ and specific cost of heat are also reported in the table. Note, that the two zeotropic mixtures outperform both pure fluids with higher COP at a lower specific cost of heat. The working fluids to include in the present study were selected with the purpose of assessing the impact of maldistribution for a diverse range of refrigerants, with different thermo-physical properties and operating pressures.

Table 4: Heat pump design and operating parameters for the selected working fluids

\begin{tabular}{|c|c|c|c|c|c|c|c|c|c|c|c|c|}
\hline \multirow[b]{2}{*}{ Working fluid } & \multicolumn{5}{|c|}{ Inputs } & \multicolumn{7}{|c|}{ Outputs } \\
\hline & $\underset{\mathrm{kW}}{\dot{Q}_{\text {eva }},}$ & $\begin{array}{c}T_{\mathrm{hs}, \text { in }}, \\
{ }^{\circ} \mathrm{C}\end{array}$ & $\begin{array}{c}T_{\mathrm{hs}, \text { out }} \text {, } \\
{ }^{\circ} \mathrm{C}\end{array}$ & $\underset{{ }_{\text {sink, in }}^{\circ},}{{ }^{\circ}}$ & $T_{\text {sink,out }}$, & $\begin{array}{c}\dot{Q}_{\text {cond }}, \\
\text { kW }\end{array}$ & $\begin{array}{c}p_{\text {cond }}, \\
\text { bar }\end{array}$ & $\begin{array}{c}p_{\text {eva }}, \\
\text { bar }\end{array}$ & $\begin{array}{c}\dot{m}, \\
\mathrm{~kg} \mathrm{~s}^{-1}\end{array}$ & $\begin{array}{l}\dot{V}_{\text {out,eva }}, \\
\mathrm{m}^{3} \mathrm{~h}^{-1}\end{array}$ & $\begin{array}{c}\text { COP, } \\
-\end{array}$ & $\begin{array}{c}c_{h}, \\
€ / \mathrm{MWh}\end{array}$ \\
\hline Butane & 500 & 50 & 25 & 50 & 75 & 630 & 9.5 & 2.2 & 1.69 & 1100 & 4.5 & 32.7 \\
\hline Propane & 500 & 50 & 25 & 50 & 75 & 638 & 28.1 & 8.8 & 1.90 & 370 & 4.4 & 31.1 \\
\hline Propylene/Butane(0.5/0.5) & 500 & 50 & 25 & 50 & 75 & 600 & 16.4 & 5.6 & 1.62 & 460 & 5.6 & 25.8 \\
\hline $\mathrm{CO}_{2} / \mathrm{DME}(0.2 / 0.8)$ & 500 & 50 & 25 & 50 & 75 & 600 & 25.3 & 9.7 & 1.56 & 290 & 5.6 & 25.4 \\
\hline
\end{tabular}

\subsubsection{Heat pump design}

The design parameters and assumptions are reported in Table 5. The sizing was carried out by fixing the heat source side, since a nominal cooling load must be provided to the data centre and the heat released to the sink (DH network) was considered as a subsequent revenue. A minimum superheat was ensured at the evaporator outlet, e.g. the temperature of the refrigerant was increased of $\Delta T_{\mathrm{SH}}$ in order to avoid refrigerant liquid droplets at the compressor inlet. The subcooling was defined to reach the highest possible COP by maximizing it and reaching the imposed pinch point temperature difference at the liquid outlet of the condenser. The compressor was assumed to have no heat losses to the environment, and typical values of isentropic and motor efficiencies were considered. 
Table 5: Assumptions and design parameters for the case study

\begin{tabular}{lccc}
\hline Description & Parameter & Value & Unit \\
\hline Evaporator & & & \\
Medium source & & water & - \\
Pinch point temperature difference & $\Delta T_{\text {pinch }}$ & 3 & $\mathrm{~K}$ \\
Minimum superheat & $\Delta T_{S \mathrm{H}}$ & 5 & $\mathrm{~K}$ \\
Design load & $\dot{Q}$ & 500 & $\mathrm{~kW}$ \\
\hline Condenser & & & \\
Medium sink & & water & - \\
Pinch point temperature difference & $\Delta T_{\text {pinch }}$ & 3 & $\mathrm{~K}$ \\
Subcooling & $T_{\text {ref,out }}$ & $T_{\text {sink,in }}+\Delta T_{\text {pinch }}$ & $\mathrm{K}$ \\
\hline Compressor & & & \\
Isentropic efficiency & $\eta_{\text {is }}$ & 0.75 & - \\
Motor efficiency & $\eta_{\text {motor }}$ & 0.95 & - \\
\hline
\end{tabular}

\subsubsection{Heat exchangers design}

The PHE design for both evaporator and condenser was carried out by considering typical plate dimensions from commercial manufacturers (ALFA LAVAL, 2018; SWEP International AB, 2015). The plate size and models are reported in Table 6. Note that different plate geometries were assumed for the different working fluids, due to the large differences in required heat transfer area. Mixtures usually require a larger area and hence investment, due to the lower temperature differences in the HEXs and the degradation of heat transfer coefficients compared to pure fluids. Therefore, plates with the larger area were selected for both propylene/butane and $\mathrm{CO}_{2} / \mathrm{DME}$ for the evaporator and condenser side. For the evaporator, a plate size with a lower aspect ratio $\left(L_{p} / W\right)$ was chosen for the pure fluids, due to the larger sensitivity of butane to pressure drop. On the other hand, the two condenser sizes were chosen with similar length-to-width ratios.

Table 6: Evaporator and condenser plate geometry, input for the design models (ALFA LAVAL, 2018; SWEP International AB, 2015)

\begin{tabular}{lcccc|cccc}
\hline \multirow{2}{*}{ Working fluid } & \multicolumn{4}{c}{ Evaporator } & \multicolumn{4}{c}{ Condenser } \\
& HEX model & $\begin{array}{c}W, \\
\mathrm{~m}\end{array}$ & $\begin{array}{c}L_{p}, \\
\mathrm{~m}\end{array}$ & $\begin{array}{c}L_{p} / W, \\
-\end{array}$ & HEX model & $\begin{array}{c}W, \\
\mathrm{~m}\end{array}$ & $L_{p}$, & $L_{p} / W$, \\
$\mathrm{m}$ & - \\
\hline Butane & SWEP B633 & 0.537 & 0.593 & 1.1 & SWEP V65 & 0.363 & 0.731 & 2.0 \\
Propane & SWEP B633 & 0.537 & 0.593 & 1.1 & SWEP V65 & 0.363 & 0.731 & 2.0 \\
Propylene/Butane $(0.5 / 0.5)$ & SWEP B649 & 0.537 & 0.995 & 1.9 & AQ6-FG & 0.650 & 1.390 & 2.1 \\
$\mathrm{CO}_{2} / \mathrm{DME}(0.2 / 0.8)$ & SWEP B649 & 0.537 & 0.995 & 1.9 & AQ6-FG & 0.650 & 1.390 & 2.1 \\
\hline
\end{tabular}

\subsubsection{Economic boundary conditions}

As the design of the HEXs and compressor was fixed by the nominal heat pump conditions, the total capital investment of the heat pump was not affected by the off-design operation. The assumptions and cost correlations used in order to estimate the TCI are described in Zühlsdorf et al. (2019).

The operating cost and revenue streams were on the other hand influenced by maldistribution. The different boundary conditions adopted for the calculations are reported in Table 7. A fixed number of yearly $\mathrm{OH}$ was assumed, since the heat pump was designed for waste heat recovery and the income from the supplied heat to the $\mathrm{DH}$ was considered as an additional benefit of the heat pump integration. The specific revenue from the heat source was assumed equal to zero. 
Table 7: Economic boundary conditions for the case study (Zühlsdorf et al., 2019)

\begin{tabular}{lccc}
\hline Description & Parameter & Value & Unit \\
\hline Lifetime & $n_{\mathrm{hp}}$ & 20 & $\mathrm{y}$ \\
Operating hours & $\mathrm{OH}$ & 8000 & $\mathrm{~h} \mathrm{y}^{-1}$ \\
Effective interest rate & $i_{\mathrm{eff}}$ & 5 & $\%$ \\
Specific cost of electricity & $c_{\mathrm{el}}$ & 120 & $\in \mathrm{MWh}^{-1}$ \\
Specific revenue of heat source & $c_{\mathrm{hs}}$ & 0 & $€ \mathrm{MWh}^{-1}$ \\
Specific income per supplied heat & $c_{\text {sink }}$ & 40 & $\in \mathrm{MWh}^{-1}$ \\
\hline
\end{tabular}

\section{Results}

This section presents the results obtained by applying the simulation framework to the case study. Subsection 3.1 presents the results of the PHE sizing for both evaporator and condenser, as a basis for the subsequent off-design analysis. Subsection 3.2 presents the impact of the imposed maldistribution on the working fluid mass flow distribution and evaporator performance, while subsection 3.3 explains the impact on the thermodynamic cycle performance. Last, subsection 3.4 reports the results of the economic analysis for one of the working fluids.

\subsection{Evaporator and condenser designs}

Table 8 shows the output of the design models. The total number of channels and heat transfer area was estimated, which gives an indication of the size of the components for each case and refrigerant. The effective heat flow rate, the mass flux, and the total refrigerant pressure drop were additional outputs of the design process. These results are dependent on the plate base design that was chosen for the working fluids. Commercial plates from manufacturers were considered, hence the PHE design was not based on a full optimization of the geometry but it was in fact based on heuristics in accordance with typically accepted values of refrigerant pressure drop. This approach resulted in designs with a different number of channels for the four refrigerants. A full optimization of the PHE geometry was considered as outside the scope of the present work.

The evaporator design for the two pure fluids butane and propane led to refrigerant pressure drop within the usual $50 \mathrm{kPa}$ limit adopted by commercial manufacturers (SWEP International AB, 2015). Despite the evaporator for butane was designed with a mass flux $\left(G_{\text {ref }}\right)$ equal to around half of the case of propane, similar pressure drops were obtained for the two fluids. This constitutes a first indication of the higher sensitivity to pressure drop of butane, i.e. a higher degradation of the PHE performance due to pressure drop is expected even if no maldistribution effect is accounted for. This will be further explained in section 3.2.

The two zeotropic mixtures led to opposite PHE designs, despite the same plate geometry was assumed in both cases. The design for propylene/butane entailed higher pressure drop (equal to $63.5 \mathrm{kPa}$ ) and a lower heat transfer area, whereas low pressure drop and bigger heat transfer area was obtained for the case of $\mathrm{CO}_{2} / \mathrm{DME}$. This is likely to lead to different impact of maldistribution for the two working fluids.

It is noted, that the condenser pressure drop predicted using the correlation by Yan et al. (1999) is very low for all the working fluids, and in the case of propane equal to $-0.86 \mathrm{kPa}$. The design of the condenser presented in this case study corresponds however to a case with a large refrigerant sub-cooling, equal to $24.3 \mathrm{~K}$ and $21.3 \mathrm{~K}$ at the design point for butane and propane, respectively, and $8.7 \mathrm{~K}$ and $2.0 \mathrm{~K}$ for propylene/butane and $\mathrm{CO}_{2} / \mathrm{DME}$. The large sub-cooling results in dominant contribution of gravity pressure drop, which in turn, for downward-flow condensers, negatively contributes to the total value (i.e. results in a pressure recovery). Note that the dominant contribution of gravity pressure drop was obtained as a consequence of using the correlation by Yan et al. (1999)(due to the low values of friction factor), and the choice of other prediction methods might change the result. This point is further discussed in section 4. 
Table 8: Results of design model for evaporator and condenser

\begin{tabular}{lccccc|ccccc}
\hline \multirow{2}{*}{ Working fluid } & \multicolumn{4}{c}{ Evaporator } & \multicolumn{4}{c}{ Condenser } \\
& $\begin{array}{c}N_{\text {ch,tot }}, \\
-\end{array}$ & $\begin{array}{c}A_{\mathrm{ht}}, \\
\mathrm{m}^{2}\end{array}$ & $\begin{array}{c}\dot{Q}, \\
\mathrm{~kW}\end{array}$ & $\begin{array}{c}G_{\text {ref }}, \\
\mathrm{kg} \mathrm{m}^{-2} \mathrm{~s}^{-1}\end{array}$ & $\begin{array}{c}\Delta p_{\text {ref,tot }}, \\
\mathrm{kPa}\end{array}$ & $\begin{array}{c}N_{\text {ch,tot }}, \\
-\end{array}$ & $\begin{array}{c}A_{\mathrm{ht}}, \\
\mathrm{m}^{2}\end{array}$ & $\begin{array}{c}\dot{Q}, \\
\mathrm{~kW}\end{array}$ & $\begin{array}{c}G_{\text {ref, }}, \\
\mathrm{kg} \mathrm{m}^{-2} \mathrm{~s}^{-1}\end{array}$ & $\begin{array}{c}\Delta p_{\text {ref,tot }}, \\
\mathrm{kPa}\end{array}$ \\
\hline Butane & 61 & 22.3 & 501 & 57.4 & 28.8 & 161 & 49.2 & 633 & 29.0 & 0.01 \\
Propane & 39 & 14.3 & 502 & 100.8 & 34.0 & 210 & 65.8 & 638 & 23.2 & -0.86 \\
Propylene/Butane (0.5/0.5) & 33 & 20.8 & 501 & 91.2 & 63.5 & 51 & 55.3 & 603 & 47.6 & 2.32 \\
$\mathrm{CO}_{2}$ /DME (0.2/0.8) & 65 & 41.0 & 500 & 44.6 & 10.9 & 51 & 55.3 & 602 & 45.8 & 0.55 \\
\hline
\end{tabular}

\subsection{Impact on evaporator performance}

Fig. 6 shows the mass flow rate distribution of the refrigerant into the different channels of the evaporator. The different colors represent the degree of maldistribution imposed by the model. $\Delta x=0$ corresponds to a uniform vapour quality distribution, thus indicating the effect of end plates on the channel-to-channel mass flow distribution. $\Delta x=0.25$ corresponds instead to the most severe maldistribution imposed by the model, namely an absolute difference of vapour quality at the inlet of the outer-most channels of 0.25 . The results are reported in terms of percentage deviation from the average mass flow rate, e.g. the mass flow rate in each channel if an equal distribution was attained.

$\longrightarrow \rightarrow--\Delta \mathrm{x}=0.00-\rightarrow-\cdot \Delta \mathrm{x}=0.05-\rightarrow-\cdot \Delta \mathrm{x}=0.10-\rightarrow-\Delta \mathrm{x}=0.15-\rightarrow-\cdot \Delta \mathrm{x}=0.20-\rightarrow--\Delta \mathrm{x}=0.25$

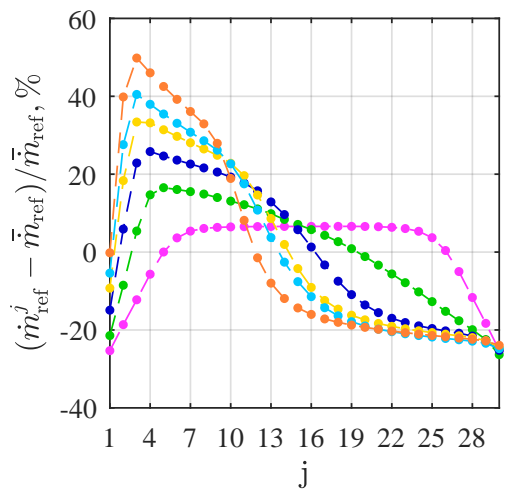

(a) Butane

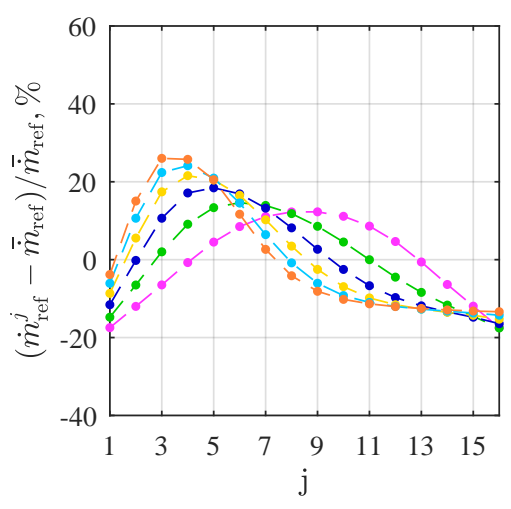

(c) Propylene/Butane $(0.5 / 0.5)$

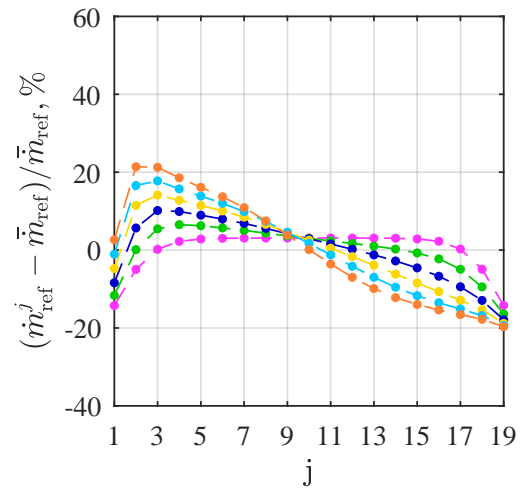

(b) Propane

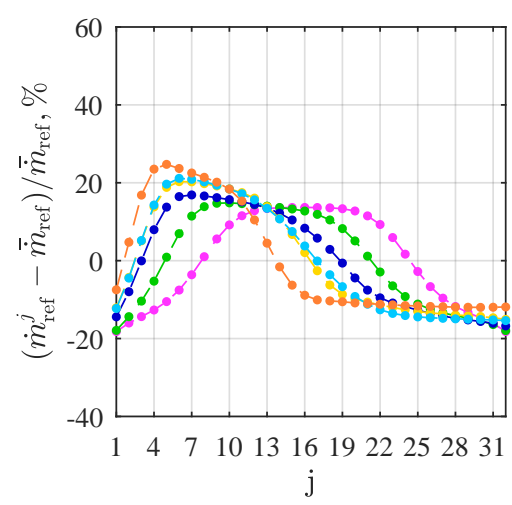

(d) $\mathrm{CO}_{2} / \mathrm{DME}(0.2 / 0.8)$

Figure 6: Mass flow distribution of the refrigerant in the different evaporator channels, shown as percentage deviation from the average value 
The trends were similar for both pure fluids and mixtures, with larger mass flow rates flowing in those channels with lower inlet vapour quality (see Fig.5). The higher pressure drop entailed by the vapour phase leads to a reduction of the mass flow rate in those channels where complete evaporation is reached earlier, in order to equalize the pressure drops. Butane showed the largest sensitivity to maldistribution, with mass flow rate deviation of up to $50 \%$ for $\Delta x=0.25$. The maximum deviation of the other working fluids resulted to be similar, with maximum values around $20 \%$ to $30 \%$.

Fig. 7 reports the total refrigerant mass flow rate (a), the total evaporator heat flow rate (b) and the total refrigerant pressure drop (c), as a function of the maldistribution parameter $\Delta x$. In Fig. 7 (a) and (b), the values were normalized with respect to the design point, which were presented in Table 4. The refrigerant pressure drop in Fig.7 (c) was instead plotted as absolute values in order to show the ranking of the working fluids.

The dashed lines in Fig. 7 represent the results of an evaporator 1D performance model, where the flow was assumed to distribute perfectly uniformly between the different channels. Therefore, the difference between the design value and the 1D performance model accounts for the real operation of the heat pump, in which pressure drops of both evaporator and condenser affect the operating conditions, i.e. pressure levels and mass flow rate, due to the imposed control parameters, which were set as a fixed superheat, subcooling and compressor suction volume flow rate. On the other hand, the difference between the dashed line and the point marker at $\Delta x=0$ quantifies the effect of end plates. The third and fourth columns of Table 9 report these differences in terms of percentage deviation for the evaporator heat flow rate. The trend outlined by the point markers in Fig. 7 represent instead the effect of liquid/vapour maldistribution. The last two columns of Table 9 report the degradation of heat flow rate in the most severe case of maldistribution $(\Delta x=0.25)$, compared to the case of uniform vapour quality distribution $(\Delta x=0)$ and to the results of the 1D model, respectively. The former solely quantifies the effect of liquid/vapour maldistribution, i.e. the slope of the degradation, while the latter reports the overall degradation due to end plates and liquid/vapour non-uniformity effects altogether.

Fig. 7(a) shows that both pure fluids - butane and propane - and the mixture propylene/butane report an evident decrease of the total mass flow rate with increasing $\Delta x$, whereas the zeotropic mixture $\mathrm{CO}_{2} / \mathrm{DME}$ does not follow a clear trend. Moreover, the reduction of mass flow rate in the case of operation with no maldistribution (dotted line) was found to be very small (around $1 \%$ ) for $\mathrm{CO}_{2} / \mathrm{DME}$, slightly higher for propane (around $2.5 \%$ ) and similar for butane and propylene/butane, around $8 \%$ to $9 \%$. The impact of real system operation on the evaporator heat flow rate was analogous, as shown in Fig.7(b). Real operation is strongly dependent on the effect of refrigerant pressure drop (in both evaporator and condenser) on the cycle operating conditions, and Fig. 7(c) shows that higher pressure drop resulted in higher degradation of the mass flow and evaporator heat flow rate. Butane was found to be the only exception, with pressure drop being the second lowest after $\mathrm{CO}_{2} / \mathrm{DME}$, yet entailing a higher degradation of performance.

Regarding the effect of end plates, propylene/butane resulted to be the fluid most influenced, with a deviation of $4.8 \%$. $\mathrm{CO}_{2} / \mathrm{DME}$ follows with a deviation of $3.5 \%$, while the two pure fluids report smaller degradations. This was already shown in Fig. 6, where the mass flow distribution into the different channels was reported for the working fluids. It may be seen that the line corresponding to $\Delta x=0$ reports a lower deviation from the average mass flow rate for both butane and propane compared to the mixtures. The deviation increases then more sharply for both pure fluids with increasing $\Delta x=0$, compared to the mixtures. Fig. 6 shows indeed that the end plates affect the mixtures to a higher extent than both pure fluids, which instead resulted to be more sensitive to vapour quality maldistribution.

Liquid/vapour maldistribution in fact impacted butane to the largest extent, leading to an overall degradation of the heat flow rate of $10.5 \%$ compared to the performance estimated by the $1 \mathrm{D}$ model. Non-uniform quality distribution contributed with $8.5 \%$ degradation. Propane resulted to be the second most affected fluid with a degradation of $2.7 \%$. This is also shown by the slope of the point markers in Fig.7 (b), which is steeper for the two pure fluids. Despite the lower degradation due to vapour quality non-uniformity experienced by propylene/butane, equal to $2.4 \%$, a high impact was found for end plates effects, leading to an overall higher evaporator performance degradation of $7.0 \%$. The mixture $\mathrm{CO}_{2} / \mathrm{DME}$ resulted to be only slightly affected by liquid/vapour maldistribution, with an overall degradation of $5.1 \%$ mostly due to end plates effect.

The different sensitivity of the working fluids to real system operation, the effect of end plates and liquid/vapour maldistribution can be related to the PHE design, as well as to the different working fluid properties. The refrigerant pressure drop trends are highlighted in Fig.7 (c), with butane clearly showing an increase in pressure drop with increasing $\Delta x$. Table 10 reports some relevant fluid thermo-physical properties, evaluated at the evaporator design 
conditions. These were used to analyze any possible correlations between maldistribution and fluid characteristics. Brignoli et al. (2017) discussed about the effect of refrigerant thermo-physical properties on two-phase heat transfer and pressure drop. The authors highlighted how high refrigerant vapour density impacts the total refrigerant pressure drop by lowering the saturation temperature decrease due to pressure drop. This is quantified by $d T_{\text {bubble }} / d p$, which can be estimated using the Clapeyron relation (Moran et al., 2018). Table 10 shows that butane reports vapour density nearly one third lower than propylene/butane and one forth lower than both propane and $\mathrm{CO}_{2} / \mathrm{DME}$. Moreover, $d T_{\text {bubble }} / d p$ for butane is one order of magnitude higher than for the other working fluids, which instead present similar values. This means that, despite the lower pressure drop related to the PHE design for butane, the evaporator is more affected compared to the other fluids. This explains why butane reports the higher degradation of evaporator performance due to real system operation, as well as a higher sensitivity to vapour quality non-uniformities.

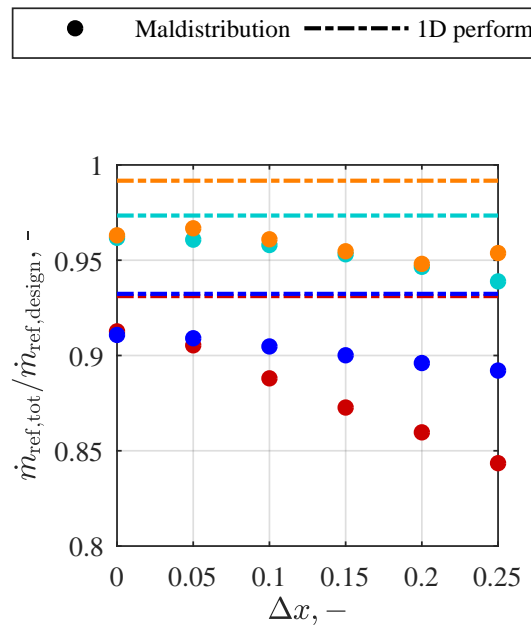

(a) Total mass flow rate

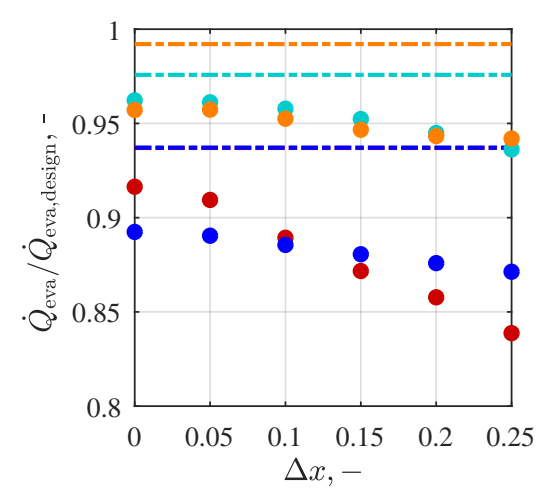

(b) Evaporator load

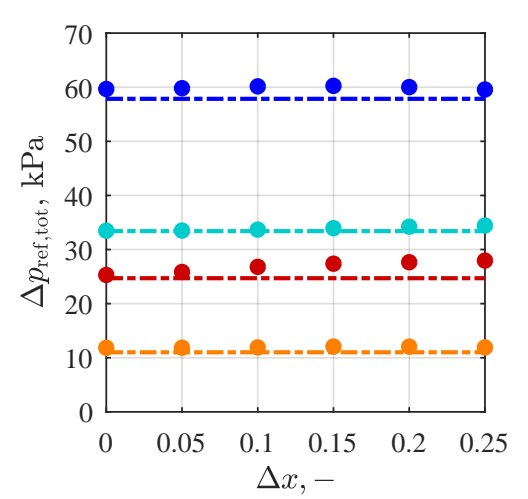

(c) Refrigerant pressure drop

Figure 7: Impact of maldistribution effects on (a) total refrigerant mass flow rate, (b) evaporator heat flow rate and (c) total refrigerant pressure drop

Table 9: Evaporator heat flow rate degradation due to effect of end plates and liquid/vapour maldistribution

\begin{tabular}{|c|c|c|c|c|c|c|}
\hline & & & real operation & $\begin{array}{l}\text { end plates } \\
\text { effect }\end{array}$ & $\begin{array}{l}\text { liquid/vapour } \\
\text { maldistribution }\end{array}$ & overall effect \\
\hline Working fluid & $\begin{array}{c}\dot{Q}_{\text {eva,design }}, \\
\mathrm{kW}\end{array}$ & $\begin{array}{c}\dot{Q}_{\text {eva }, 1 \mathrm{D}}, \\
\mathrm{kW}\end{array}$ & $\frac{\dot{Q}_{1 \mathrm{D}}-\dot{Q}_{\text {design }}}{\dot{Q}_{\text {design }}}$, & $\frac{\dot{Q}_{\Delta \mathrm{x}=0}-\dot{Q}_{1 \mathrm{D}}}{\underset{\dot{Q}_{1 \mathrm{D}}}{\%}}$, & $\frac{\dot{Q}_{\Delta \mathrm{x}=0.25}-\dot{Q}_{\Delta \mathrm{x}=0}}{\dot{Q}_{\Delta \mathrm{x}=0}}$, & $\frac{\dot{Q}_{\Delta \mathrm{x}=0.25}-\dot{Q}_{1 \mathrm{D}}}{\dot{Q}_{1 \mathrm{D}}}$ \\
\hline Butane & 500 & 468 & -6.7 & -2.2 & -8.5 & -10.5 \\
\hline Propane & 500 & 488 & -2.5 & -1.4 & -2.7 & -4.1 \\
\hline Propylene/Butane $(0.5 / 0.5)$ & 500 & 469 & -6.7 & -4.8 & -2.4 & -7.0 \\
\hline $\mathrm{CO}_{2} / \mathrm{DME}(0.2 / 0.8)$ & 500 & 496 & -0.8 & -3.5 & -1.6 & -5.1 \\
\hline
\end{tabular}


Table 10: Refrigerant saturation pressure and thermo-physical properties at evaporator design conditions

\begin{tabular}{lccccc}
\hline Working fluid & $\begin{array}{c}p_{\text {eva,design }}, \\
\text { bar }\end{array}$ & $\begin{array}{c}T_{\text {bubble }}, \\
{ }^{\circ} \mathrm{C}\end{array}$ & $\begin{array}{c}T_{\text {dew }}, \\
{ }^{\circ} \mathrm{C}\end{array}$ & $\begin{array}{c}\rho_{V}, \\
\mathrm{~kg} \mathrm{~m}^{-3}\end{array}$ & $\begin{array}{c}\frac{d T_{\text {bubble }}}{d p}, \\
\mathrm{~K} \mathrm{kPa}^{-1}\end{array}$ \\
\hline Butane & 2.2 & 22.5 & 22.5 & 5.7 & 0.140 \\
Propane & 8.8 & 22.0 & 22.0 & 19.1 & 0.044 \\
Propylene/Butane $(0.5 / 0.5)$ & 5.6 & 19.8 & 37.0 & 13.6 & 0.054 \\
$\mathrm{CO}_{2} / \mathrm{DME}(0.2 / 0.8)$ & 9.7 & 11.2 & 34.9 & 20.1 & 0.033 \\
\hline
\end{tabular}

\subsection{Impact on cycle thermodynamic performance}

A degradation of evaporator performance due to maldistribution effects influences the performance of the overall thermodynamic cycle. Fig. 8 shows the effect of the different rates of imposed vapour quality non-uniformity on total condenser heat flow rate (a), on the power required by the compressor (b) and the COP (c), defining the heat pump thermodynamic performance.

The condenser load estimated by the 1D performance model, thereby accounting for pressure drops of both evaporator and condenser, was found to be lower than the design value for all working fluids. Similarly to the evaporator case, the decrease for butane and propylene/butane was found to be higher, around $5 \%$ vs. a decrease of around $1 \%$ to $2 \%$ for propane and nearly negligible for $\mathrm{CO}_{2} / \mathrm{DME}$. This was due to the higher sensitivity of butane to pressure drop and the highest value of pressure drop for propylene/butane as already presented in the previous section. The end plate effects in the evaporator for both butane and propylene/butane translate into similar values of condenser load reduction, yet the slope of butane was the steepest among all the working fluids. This is consistent with the results presented in Table 9, which showed butane being the most affected fluid regarding liquid/vapour maldistribution. $\mathrm{CO}_{2}$ /DME does not follow a clearly decreasing trend, similarly to what was found for the total refrigerant mass flow rate in Fig. 7 (a).

The effect of maldistribution on the power required by the compressor in Fig. 8 (b) shows that propane, propylene/butane and $\mathrm{CO}_{2} / \mathrm{DME}$ were negligibly affected by maldistribution, while butane underwent a visible decrease ( $2 \%$ to $3 \%$ ). This is due to the opposite effects of the mass flow reduction (shown in Fig. 7 (a)) and an increase of pressure ratio and reduction of isentropic efficiency during off-design operation. The mass flow rate reduction is the dominating effect for butane, thus entailing a lower compressor power, whereas the other working fluids resulted to have a counteracting effect from mass flow rate and pressure ratio/efficiency, thereby having nearly constant compressor power.

The condensation heat flow rate reduction together with the different trends from the compressor power affected the resulting heat pump COP, shown in Fig. 8 (c). The percentage deviations are reported in Table 11, similarly to the evaporator case, i.e. by estimating the effect of real operation, end plates and vapour quality non-uniformity separately and altogether.

The effect of maldistribution on COP follows the same trend as the condenser heat flow rate for propane, propylene/butane and $\mathrm{CO}_{2} / \mathrm{DME}$, since the compressor power was not affected. The decrease of condenser heat flow rate was found to be dominating over the reduction of power consumption for butane, thereby entailing a COP reduction. The effect of end plates was however reduced compared to the evaporator, and the slope of the maldistribution rates (increasing $\Delta x$ ) is less steep.

By comparing the last columns of Tables 9 and 11, it may be observed that the PHE evaporator degradation was translated into a lower effect on the COP for all the working fluids, comparable to half of the evaporator degradation. The difference between the design and 1D model was reduced, as well as the effect of end plates, compared to the evaporator performance degradation. The relative ranking of the fluids with respect to each other was maintained, hence butane experienced the largest reduction of COP equal to $5.9 \%$, followed by propylene/butane, $\mathrm{CO}_{2} / \mathrm{DME}^{\mathrm{and}}$ propane.

The effect of maldistribution on the cycle thermodynamic performance is additionally presented in Fig. 9 by the $\log (p)-h$ diagram of the heat pump cycle at the design point compared to the different cases of maldistribution. Fig. 9 shows the case of butane, since it resulted as the most sensitive fluid to maldistribution. The trends for the other refrigerants were found to be similar. In agreement with the results shown in Fig. 7 (c), increasing $\Delta x$ entails an increase of refrigerant pressure drop at the evaporator, as clearly shown by the evaporator outlet state point 
reported in the $\log (\mathrm{p})$-h diagram. Fig. 9 shows that the cycle operation is significantly affected by the occurrence of maldistribution effects.

- Maldistribution --ー-ー-- 1D performance model $\longrightarrow$ Butane $\longrightarrow$ Propylene/Butane $\longrightarrow \mathrm{CO}_{2} / \mathrm{DME}^{\longrightarrow}$

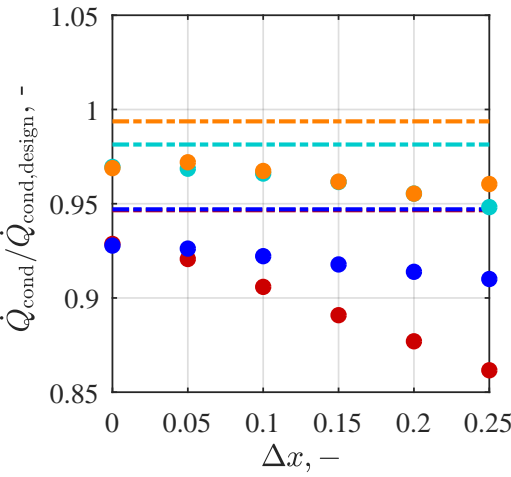

(a) Condenser load

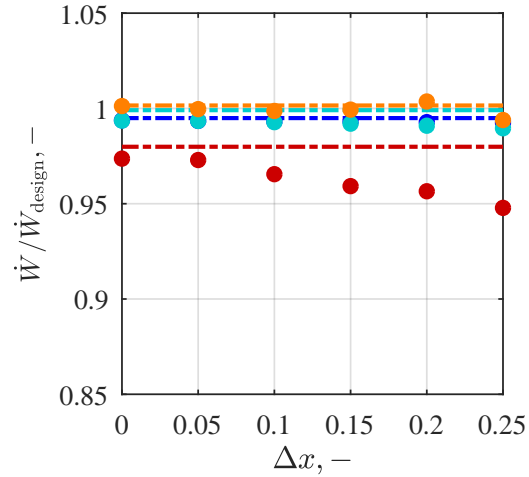

(b) Compressor power

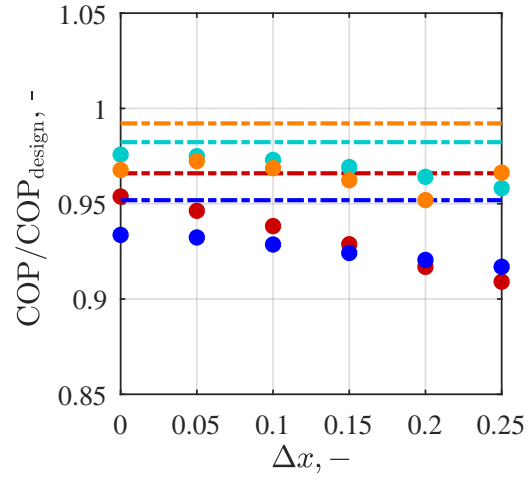

(c) $\mathrm{COP}$

Figure 8: Impact of maldistribution effects on (a) condenser heat flow rate, (b) compressor power and (c) heat pump COP

Table 11: COP degradation due to effect of end plates and liquid/vapour maldistribution

\begin{tabular}{|c|c|c|c|c|c|c|}
\hline \multirow{3}{*}{ Working fluid } & \multirow{3}{*}{$\mathrm{COP}_{\text {design }}$} & \multirow{3}{*}{$\mathrm{COP}_{1 \mathrm{D}}$} & real operation & \multicolumn{2}{|r|}{$\begin{array}{l}\text { liquid/vapour } \\
\text { maldistribution }\end{array}$} & \multirow[t]{2}{*}{ overall effect } \\
\hline & & & $\mathrm{COP}_{1 \mathrm{D}}-\mathrm{COP}_{\text {design }}$ & $\mathrm{COP}_{\Delta \mathrm{x}=0}-\mathrm{COP}_{1 \mathrm{D}}$ & $\mathrm{COP}_{\Delta \mathrm{x}=0.25}-\mathrm{COP}_{\Delta \mathrm{x}=0}$ & \\
\hline & & & $\mathrm{COP}_{\text {design }}$ & $\mathrm{COP}_{1 \mathrm{D}}$ & $\mathrm{COP}_{\Delta \mathrm{x}=0}$ & $\mathrm{COP}_{1 \mathrm{D}}$ \\
\hline Butane & 4.52 & 4.37 & -3.4 & -1.3 & -4.7 & -5.9 \\
\hline Propane & 4.40 & 4.32 & -1.8 & -0.7 & -1.8 & -2.5 \\
\hline Propylene/Butane $(0.5 / 0.5)$ & 5.58 & 5.31 & -4.8 & -1.9 & -1.8 & -3.7 \\
\hline $\mathrm{CO}_{2} / \mathrm{DME}(0.2 / 0.8)$ & 5.63 & 5.59 & -0.7 & -2.5 & -0.1 & -2.6 \\
\hline
\end{tabular}
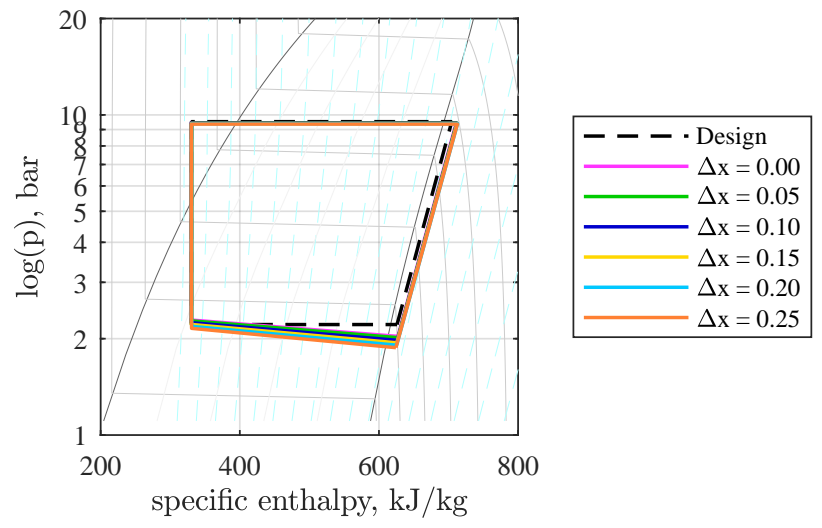

Figure 9: Impact of maldistribution effects on the heat pump cycle for butane 


\subsection{Economic analysis}

The results of the economic analysis are presented solely for butane. The other working fluids showed similar trends yet with different magnitude of the impact. Moreover, the results of the economic analysis serve as a mere indication of the utilization of the simulation framework presented in this paper, since they are dependent on the assumptions made for the specific case study.

The economic performance indicator introduced by Eq.(3), namely the specific cost of heat, is shown in Fig. 10(a), while the two different revenue and cost streams associated with the chosen case study are reported in Fig. 10(b), for design case, the heat pump real operation and the different maldistribution rates. Since the heat pump was assumed to be operated for a fixed number of hours, the specific cost of heat was found to increase due to maldistribution effects. The heat load of the condenser (presented in Fig. 8 (a)) resulted to be decreasing with increasing $\Delta x$, and had a dominating effect compared to the decrease in operating costs associated to the compressor. The heat source was considered to be free excess heat from a data centre, while the TCI was fixed in all the cases, hence constituting the heat sink and compressor costs to be the only influencing factors. Fig.10(b) shows the yearly electricity cost of the compressor compared to the revenue stream (which is not considered for the computation of $c_{h}$ ). The revenue stream was determined by the heat of the condenser, which was supplied to the DH network. In agreement with the increasing trend of the specific cost of heat, the revenue stream was found to decrease with a steeper slope compared to the compressor running costs, thereby leading to an increase in the operation cost of the heat pump when maldistribution affects the operation of the evaporator.

\section{- Maldistribution — Design $---\cdot$ 1D performance model $\longrightarrow$ Cost of electricity — Income from supplied heat}

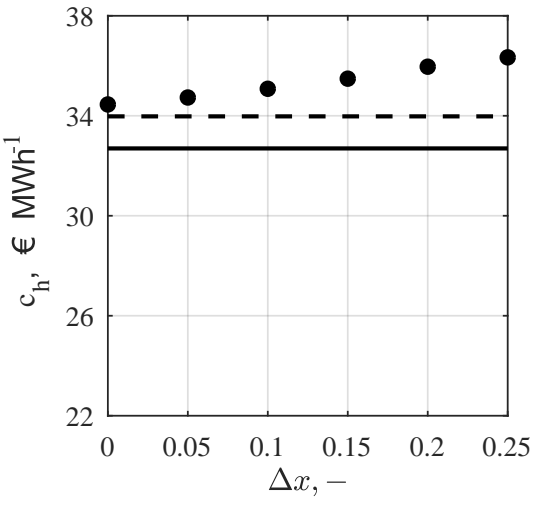

(a) Specific cost of heat

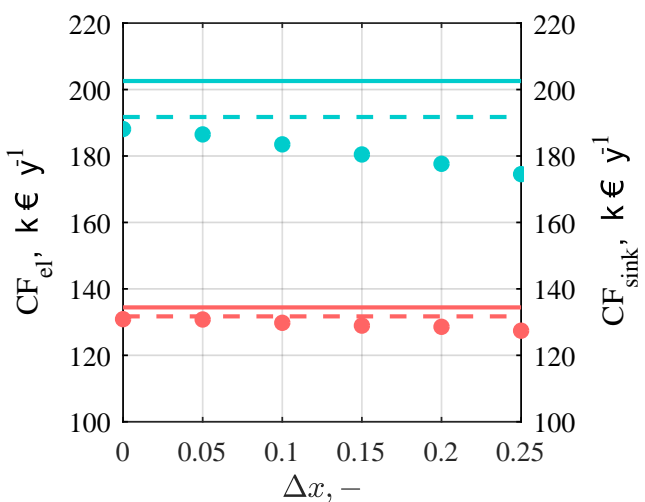

(b) Cost/revenue streams

Figure 10: (a) Specific cost of heat and (b) yearly cost and revenue streams as function of $\Delta x$ for butane

\section{Discussion}

The results presented in this paper showed the application of a coupled PHE-cycle simulation framework, which can be used for system design and operation analysis when maldistribution occurs in PHE evaporators. The application of the procedure was demonstrated step-by-step for a case study and four different working fluids.

The results showed a general degradation of the evaporator and cycle performance both due to the effects of end plates and liquid/vapour maldistribution. The differences between working fluids were presented in light of several aspects contributing to such discrepancies, namely PHE design, obtained pressure drop and fluid properties.

The PHE design was carried out by fixing the plate geometry to typical dimensions available from suppliers, no numerical optimization was carried out for any working fluids and the designs were chosen to respect typical allowable limits for pressure drop. Since the pressure drop, which is strongly influenced by the geometry, was found to affect the refrigerant sensitivity to maldistribution effects, the results should not be taken as a final ranking of the 
different refrigerants. The results were instead presented as a way to use the simulation framework and to understand the different aspects to take into consideration during design and analysis of both evaporator and cycle. For instance, by looking at the results for PHE design for the two mixtures propylene/butane and $\mathrm{CO}_{2} / \mathrm{DME}$ in Table 8 , it can be observed that opposite evaporator designs were obtained: propylene/butane resulted in a configuration with a low number of channels, thereby higher pressure drop and low heat transfer area, whereas for $\mathrm{CO}_{2} / \mathrm{DME}$ a higher plates number was employed, entailing higher heat transfer area and low pressure drop. It was therefore found that a lower evaporator investment could be required for propylene/butane. The maldistribution study showed however that propylene/butane, with this particular PHE design, experienced evaporator heat flow rate reduction of up $7 \%$, leading to a $3.7 \%$ decrease of the system COP. The design for $\mathrm{CO}_{2} / \mathrm{DME}$ was instead found to entail lower effects of maldistribution, leading to maximum $2.6 \%$ reduction of COP, almost entirely due to end plates. This means that, case by case, the trade-off between pressure drop and area investment must be decided also taking maldistribution effects into account, since they may impact the evaporator and cycle performance considerably, depending on the PHE geometry and pressure drop limit chosen during the design phase.

Moreover, the results of the study showed that the thermo-physical properties of the refrigerant are a relevant aspect to consider. Brignoli et al. (2017) already stressed the importance of taking fluid characteristics into account to discriminate when combined optimization of cycle and HEX design leads to an effective increase of the cycle thermodynamic performance. They showed how a higher margin of COP improvement was obtained for those fluids for which increasing mass fluxes entailed a higher increase of heat transfer coefficient compared to pressure drop. They additionally discussed how some fluid properties, such as vapour density and refrigerant temperature drop due to pressure drop, were influencing the trends. Maldistribution is another aspect to consider, since non-favourable thermo-physical properties (like the ones showed for butane in Table 10) implied higher performance degradation due to such effects. Choosing a PHE design leading to a lower impact of both end plates and liquid/vapour maldistribution is therefore particularly relevant for fluids with higher pressure drop sensitivity. For example optimizing the PHE design for butane in the chosen case study, would likely lead to higher benefits in terms of performance improvement compared to the other working fluids. This must also be considered when choosing empirical design criteria to size PHE, e.g. limiting velocities or pressure drop. Mancini et al. (2018c) showed how the usually employed design approaches do not necessarily lead to an optimal design for different working fluids, since different refrigerants are differently sensitive to pressure drop. This is in agreement with the findings of this work, which further stresses the importance of understanding maldistribution effects and of discriminating if it is relevant to consider them or to optimize the PHE design.

It is relevant to mention that the application of the simulation framework consisted of an economic analysis to study the effect of maldistribution on the operating costs of the heat pump. The results are strongly dependent on the assumption of this particular case study, especially regarding the values chosen for electricity cost and revenue from selling heat. Moreover, it was considered that the heat source comes at no cost from internal excess heat recovery from the data centre. These assumptions might completely change for different applications of heat pump integration, thereby stressing again that the economic analysis must be solely taken as an explanatory example of the procedure presented in the paper.

This study was focused on maldistribution effects in PHE evaporators only, thus neglecting potential maldistribution issues related to condenser design. Specifically, no liquid/vapour non-uniform distribution can occur at the condenser inlet, since the refrigerant is superheated vapour, hence only the effect of end plates may potentially be considered. Previous study by Zühlsdorf et al. (2018a) showed however that evaporator design affects the performance of heat pumps using mixed refrigerant to a larger extent compared to the condenser, and it was thus decided to limit the focus of this study on evaporator performance only.

Note that liquid/vapour maldistribution was evaluated by carrying out a sensitivity study on different slopes of vapour quality variation at the channel inlets. This was based on the assumption of linear vapour quality profiles, as experimentally shown for tubular manifolds for compact HEXs in Vist \& Pettersen (2004). Moreover, a maximum variation of 0.25 was imposed as input to the model. Further experiments should therefore be carried out in order to validate the linear assumptions, as well as the slope of the distribution. Both evaporator and heat pump COP resulted to be largely affected, by limiting the maximum difference of the inlet vapour quality to 0.25 , with maximum deviations due to liquid/vapour maldistribution obtained for butane of $-8.5 \%$ and $4.7 \%$, respectively. For a higher degree of maldistribution, it is thus expected to obtain even larger degradation of both PHE and heat pump performance.

Though not the focus of the present study, it is important to point out one aspect of condenser design and pressure 
drop prediction. The results of Table 8 showed that the frictional pressure drop evaluated using the Yan et al. (1999) correlation resulted in very low values of the frictional contribution. This led, for the case of propane, to have a dominant effect of gravity pressure recovery. However, it is again stressed that the conclusion on the dominating effect of gravity pressure recovery is strictly related to the chosen prediction method for frictional pressure drop, and using correlations recently published by Tao \& Ferreira (2019) or Zhang et al. (2019) could lead to opposite results. However, Mancini et al. (2019) showed that the influence of condenser pressure drop is not relevant for the heat pump COP of the same case study and fluids considered in the present paper. The results on evaporator maldistribution effects presented in this paper are thus not sensitive to the chosen prediction method and to the resulting condenser design.

\section{Conclusions}

A coupled PHE-heat pump modelling framework was developed to evaluate the impact of end plates and liquid/vapour maldistribution at the inlet of PHE evaporators on heat transfer performance, heat pump COP and costs. A maldistribution parameter $\Delta x$ was defined to describe the vapour quality difference between the outer-most evaporator channels. The procedure was applied to a case study, for which the pure fluids butane and propane and the two zeotropic mixtures propylene/butane and $\mathrm{CO}_{2} / \mathrm{DME}$ were previously found as optimal working fluids.

A general reduction of the evaporator heat flow rate was obtained as a result of end plate effects. Propylene/butane was found as the working fluid that was most sensitive to end plates, with a $4.8 \%$ reduction of evaporator heat flow rate, followed by $\mathrm{CO}_{2} / \mathrm{DME}$ and the two pure fluids. Butane was instead most sensitive to liquid/vapour maldistribution, with an impact equal to $-8.5 \%$, leading to an overall evaporator performance reduction of $-10.5 \%$. The high sensitivity was found to be related to the PHE design, and especially to the low working fluid vapour density, the higher temperature drop due to pressure drop and low evaporation pressure.

The impact of maldistribution effects was also translated into an estimation of COP degradation. The relative ranking of the working fluids was shown to be similar to the ones for the evaporator, i.e. with butane as the most sensitive fluid, with $-5.9 \%$ due to end plates and vapour quality non-uniformity effects altogether and propane the least affected $(-2.5 \%)$. The reduction of COP was lower compared to the evaporator performance degradation, around half of the value of all the working fluids.

The economic analysis showed the impact of COP reduction on the specific cost of heat, compressor running costs and revenue from the heat sink. It was shown that, despite a decrease in the electricity needed to run the compressor during off-design operation due to maldistribution, a lower yearly production of energy was achieved for a fixed number of operating hours. Therefore, an increase of the cost of heat was obtained, together with a steep drop in the revenue from selling the heat to the DH network. The economic analysis was highly dependent on the case study and related assumptions.

The results showed that both end plates and liquid/vapour maldistribution can have a considerable effect on evaporator and cycle performance, depending on the working fluid, PHE design, and case study. The presented simulation framework can be used as a comprehensive analysis tool to evaluate the impact on different PHE designs, with different rates of imposed maldistribution, on the thermodynamic and economic feasibility of heat pumps and to compare different refrigerants.

\section{Acknowledgments}

This research was funded by Innovations Fund Denmark - The Danish Council for Strategic Research in Sustainable Energy and Environment - under the project title "THERMCYC - Advanced thermodynamic cycles utilizing low temperature heat sources". The first author acknowledges the support from the Modelling and Optimization Consortium (MOC) of the Center for Environmental Energy Engineering (CEEE) at University of Maryland.

\section{Nomenclature}

\section{Abbreviations and acronyms}

$1 \mathrm{D}$
$2 \mathrm{D}$

CV

DH two-dimensional

control volume

district heating 


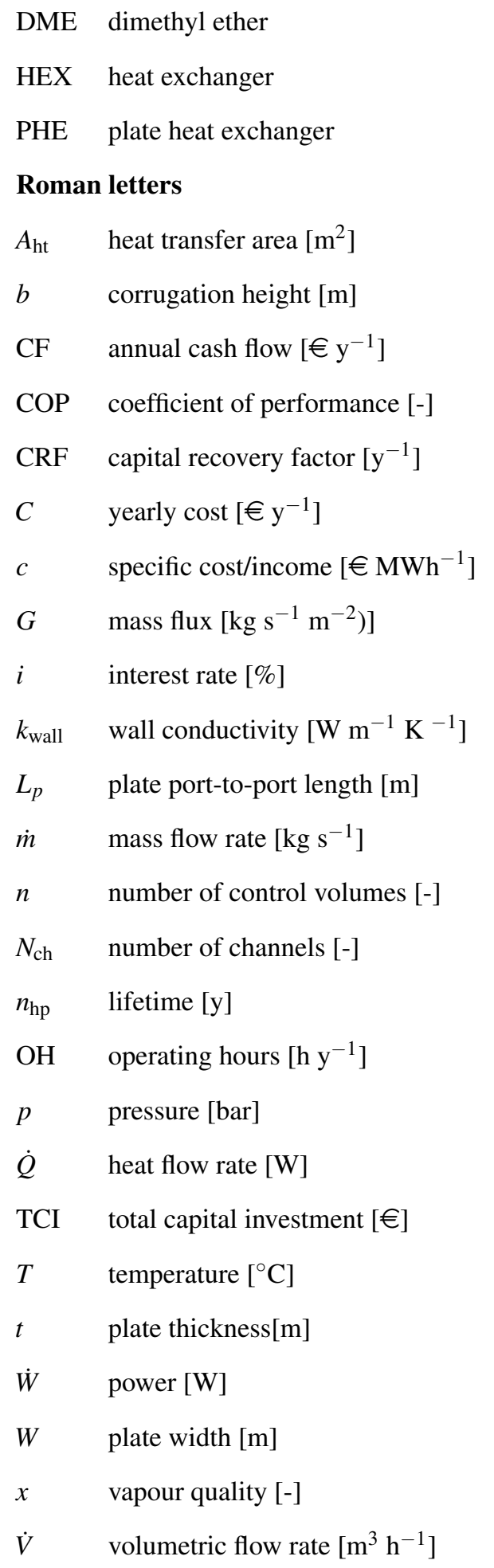

\section{Greek letters}

$\alpha \quad$ void fraction [-]

$\beta \quad$ chevron angle $\left[{ }^{\circ}\right]$
$\Delta \quad$ difference [-]
$\eta \quad$ efficiency [-]
$\Lambda \quad$ corrugation pitch [m]
$\rho \quad$ density $\left[\mathrm{kg} \mathrm{m}^{-3}\right]$

\section{Superscripts}

$i \quad$ index discretization along flow direction

$j \quad$ index discretization number of channel

\section{Subscripts}

bubble bubble

cond condenser

design design

dew dew

eff effective

el electricity

eva evaporator

gen generation

$h$ heat

hg heat generation

hs heat source

HT heat transfer

in inlet

is isentropic

min minimum

out outlet

$\Delta p \quad$ pressure drop

pinch pinch

ref refrigerant

SH superheat

sink sink

tot total

V vapour 


\section{References}

ALFA LAVAL (2018). Alfa Laval, AlfaQ series. URL: https://www.alfalaval.com/products/heat-transfer/plate-heat-exchangers/ gasketed-plate-and-frame-heat-exchangers/alfaq/.

Amalfi, R., Vakili-Farahani, F., \& Thome, J. (2016). Flow boiling and frictional pressure gradients in plate heat exchangers . Part 2: Comparison of literature methods to database and new prediction methods. International Journal of Refrigeration, 61, 185-203. doi:10.1016/j. ijrefrig. 2015.07 .009 .

Bassiouny, M., \& Martin, H. (1984a). Flow distribution and pressure drop in plate heat exchangers-I U-type arrangement. Chemical Engineering Science, 39, 693-700. doi:10.1016/0009-2509(84)80176-1.

Bassiouny, M., \& Martin, H. (1984b). Flow distribution and pressure drop in plate heat exchangers-II Z-type arrangement. Chemical Engineering Science, 39, 701-704.

Bell, I. H., Wronski, J., Quoilin, S., \& Lemort, V. (2014). Pure and pseudo-pure fluid thermophysical property evaluation and the open-source thermophysical property library coolprop. Industrial and Engineering Chemistry Research, 53, 2498-2508. doi:10.1021/ie4033999.

Bell, K., \& Ghaly, M. (1973). An approximate generalized design method for multicomponent/partial condenser. AIChE Symposium Series, 69, $72-79$.

Bobbili, P. R., Sunden, B., \& Das, S. K. (2006). An experimental investigation of the port flow maldistribution in small and large plate package heat exchangers. Applied Thermal Engineering, 26, 1919-1926. doi:10.1016/j . applthermaleng.2006.01.015.

Brignoli, R., Brown, J. S., Skye, H. M., \& Domanski, P. A. (2017). Refrigerant performance evaluation including effects of transport properties and optimized heat exchangers. International Journal of Refrigeration, 80, 52-65. doi:10.1016/j.ijrefrig.2017.05.014.

Chisholm, D. (1967). A Theoretical Basis for the Lockhart-Martinelli Correlation for Two-Phase Flow. International Journal of Heat and Mass Transfer, 10, 1767-1778. URL: http://www.sciencedirect.com/science/article/pii/0017931067900476. doi:http://dx.doi.org/10.1016/ $0017-9310(67) 90047-6$.

Cooper, M. (1984). Heat flow rates in saturated nucleate pool boiling - a wide ranging examination using reduced properties. Advances in Heat Transfer, 16, 59-156.

Eldeeb, R., Aute, V., \& Radermacher, R. (2016). An Improved Approach for Modeling Plate Heat Exchangers Based on Successive Substitution in Alternating Flow Directions. In Proceedings of the International Refrigeration and Air Conditioning Conference, Purdue university, US. URL: http://docs.lib.purdue.edu/iracc/1684.

Godbole, P. V., Tang, C. C., \& Ghajar, A. J. (2011). Comparison of void fraction correlations for different flow patterns in upward vertical two-phase flow. Heat Transfer Engineering, 32, 843-860. doi:10.1080/01457632.2011.548285.

Gong, J., Gao, T., Yuan, X., \& Huang, D. (2008). Effects of air flow maldistribution on refrigeration system dynamics of air source heat pump chiller under frosting conditions. Energy Conversion and Management, 49, 1645-1651. doi:10.1016/j .enconman.2007.11.004.

Granryd, E., Ekroth, I., Lundqvist, P., Melinder, Å., Palm, B., \& Rohlin, P. (2009). Refrigerating engineering. Royal Institute of Technology, KTH, Department of Energy Technology, Division of Applied Thermodynamics and Refrigeration.

Jensen, J. K., Kærn, M. R., Ommen, T. S., Brix, W., Reinholdt, L., \& Elmegaard, B. (2015). Effect of liquid/vapour maldistribution on the performance of plate heat exchanger evaporators. In Proceedings of the 24th IIR International Congress of Refrigeration.

Jin, S., \& Hrnjak, P. (2017a). A new method to simultaneously measure local heat transfer and visualize flow boiling in plate heat exchanger. International Journal of Heat and Mass Transfer, 113, 635-646. doi:10.1016/j . i jheatmasstransfer.2017.04.116.

Jin, S., \& Hrnjak, P. (2017b). Effect of end plates on heat transfer of plate heat exchanger. International Journal of Heat and Mass Transfer, 108, 740-748. doi:10.1016/j.ijheatmasstransfer.2016.11.106.

Kærn, M. R., Brix, W., Elmegaard, B., \& Larsen, L. F. S. (2011). Performance of residential air-conditioning systems with flow maldistribution in fin-and-tube evaporators. International Journal of Refrigeration, 34, 696-706. doi:10.1016/j . ij refrig.2010.12.010.

Lemmon, E., Bell, I., Huber, M., \& McLinden, M. (2018). NIST Standard Reference Database 23: Reference Fluid Thermodynamic and Transport Properties - REFPROP, version 10.0, . URL: https://media.readthedocs.org/pdf/refprop-docs/latest/refprop-docs.pdf.

Li, W., \& Hrnjak, P. (2016). Single Phase Pressure Drop and Flow Distribution in Brazed Plate Heat Exchangers. In International Refrigeration and Air Conditioning Conference (p. Paper 1812). Purdue university. URL: http://docs.lib.purdue.edu/iracc/1812.

Li, W., \& Hrnjak, P. (2018). An experimentally validated model of single-phase flow distribution in brazed plate heat exchanger. In 17th International Refrigeration and Air Conditioning Conference at Purdue.

Lockhart, R., \& Martinelli, R. (1949). Proposed correlation of data for isothermal two-phase, two-component flow in pipes. Chemical engineering progress, 45, 39-48.

Madanan, U., Nayak, R., Chatterjee, D., \& Das, S. K. (2018). Experimental investigation on two-phase flow maldistribution in parallel minichannels with U-type configuration. Canadian Journal of Chemical Engineering, 96, 1820-1828. doi:10.1002/cjce.23112.

Mader, G., Palm, B., \& Elmegaard, B. (2015). Maldistribution in air-water heat pump evaporators. Part 1: Effects on evaporator, heat pump and system level. International Journal of Refrigeration, 50, 207-216. doi:10.1016/j. ijrefrig.2014.07.006.

Mancini, R. (2018). Numerical models for assessing the performance of heat pumps with maldistribution effects in plate heat exchanger evaporators. URL: https://data.dtu.dk/s/74a2e50d0cf215425d26. doi:10.11583/DTU.7565279.

Mancini, R., Aute, V., Brix Markussen, W., \& Elmegaard, B. (2018a). Impact of Liquid/Vapor Maldistribution on the Performance of a Plate Heat Exchanger Evaporator for Pure and Mixed Refrigerants. In Proceedings of the 17th International Refrigeration and Air Conditioning Conference at Purdue, West Lafayette, Indiana (US).

Mancini, R., Kjær Jensen, J., Brix Markussen, W., \& Elmegaard, B. (2018b). Comparison of Heat Transfer and Pressure Drop Correlations for Evaporation of Zeotropic Mixtures in Plate Heat Exchangers. In Proceedings of the 13th IIR-Gustav Lorentzen Conference on Natural Refrigerants. International Institute of Refrigeration. doi:10.18462/iir.gl.2018.1261.

Mancini, R., Zühlsdorf, B., Kjær Jensen, J., Brix Markussen, W., \& Elmegaard, B. (2018c). Deriving guidelines for the design of plate evaporators in heat pumps using zeotropic mixtures. Energy, 156. doi:10.1016/j .energy .2018.05.026.

Mancini, R., Zühlsdorf, B., Markussen, W. B., \& Elmegaard, B. (2019). Design recommendations for plate heat exchangers in heat pumps 
using pure and mixed refrigerants. In Proceedings of the 25th IIR International Congress of Refrigeration Paper 853. Montreal, Canada. doi:10.18462/iir.icr.2019.853.

Martin, H. (1996). A theoretical approach to predict the performance of chevron-type plate heat exchangers. Chemical Engineering and Processing, 35, 301-310. doi:10.1016/0255-2701(95)04129-X.

Mathworks (2017a). fsolve - solve systems of nonlinear equations, Matlab 2017b. URL: https://www.mathworks.com/help/optim/ug/fsolve.html.

Mathworks (2017b). Matlab R2017b. URL: https://www.mathworks.com/help/matlab/.

Moran, M., Shapiro, H., Boettner, D., \& Bailey, M. (2018). Fundamentals of Engineering Thermodynamics. Wiley. URL: https://books.google.dk/ books?id=QHJIDwAAQBAJ.

Mueller, A. C., \& Chiou, J. P. (1988). Review of various Types of Flow Maldistribution in Heat Exchangers. Heat Transfer Engineering, 9, 36-50. doi:10.1080/01457638808939664.

Palm, B., \& Claesson, J. (2006). Plate Heat Exchangers: Calculation Methods for Single and Two-Phase Flow. Heat Transfer Engineering, 27, 88-98. doi:10.1080/01457630500523949.

Rao, B. P., \& Das, S. K. (2004). An Experimental Study on the Influence of Flow Maldistribution on the Pressure Drop Across a Plate Heat Exchanger. Journal of Fluids Engineering - Transaction of ASME, 126, 680-691. doi:10.1115/1.1779664.

Rao, B. P., Sunden, B., \& Das, S. K. (2005). An Experimental and Theoretical Investigation of the Effect of Flow Maldistribution on the Thermal Performance of Plate Heat Exchangers. Journal of Heat Transfer-transactions of the Asme, 127. doi:10.1115/1.1860568.

Sardesai, R. G., Shock, R. A., \& Butterworth, D. (1982). Heat and mass transfer in multicomponent condensation and boiling. Heat Transfer Engineering, 3, 104-114. doi:10.1080/01457638108939589.

Shah, R. K., \& Sekulic, D. P. (2002). Fundamentals of Heat Exchanger Design. Wiley. doi:10.1002/9780470172605.

Silver, L. (1947). Gas cooling with aqueous condensation. Industrial Chemist and Chemical Manufacturer, 23, 380-386.

Smith, S. L. (1969). Void fractions in two-phase flow: a correlation based upon an equal velocity head model. Proceedings of the Institution of Mechanical Engineers, 184, 647-664. doi:10.1243/PIME_PROC_1969_184_051_02.

Srihari, N., \& Das, S. K. (2006). Transient response of multi-pass plate heat exchangers considering effect of flow maldistribution. Chemical Engineering and Processing, 47, 695-707. doi:10.1016/j.cep. 2006.12.011.

Srihari, N., Prabhakara Rao, B., Sunden, B., \& Das, S. K. (2005). Transient response of plate heat exchangers considering effect of flow maldistribution. International Journal of Heat and Mass Transfer, 48, 3231-3243. doi:10.1016/j . i jheatmasstransfer.2005.02.032.

SWEP International AB (2015). SWEP Products. URL: https://www.swep.net/products/.

Tao, X., \& Ferreira, C. A. I. (2019). Heat transfer and frictional pressure drop during condensation in plate heat exchangers : Assessment of correlations and a new method. International Journal of Heat and Mass Transfer, 135, 996-1012. URL: https://doi.org/10.1016/j.ijheatmasstransfer. 2019.01.132. doi:10.1016/j.ijheatmasstransfer.2019.01.132.

Tereda, F. A., Srihari, N., Sunden, B., \& Das, S. K. (2007). Experimental investigation on port-to-channel flow maldistribution in plate heat exchangers. Heat Transfer Engineering, 28, 435-443. doi:10.1080/01457630601163769.

Thome, J. R., \& Shakir, S. (1987). A new correlation for nucleate pool boiling of aqueous mixtures. AIChE Symposium Series, 83, 46-51.

Vakili-Farahani, F., Amalfi, R. L., \& Thome, J. R. (2015). Two-Phase Heat Transfer and Pressure Drop within Plate Heat Exchangers. In J. R. Thome, \& J. Kim (Eds.), Encyclopedia of Two-Phase Heat Transfer and Flow II : Special topics and applications. Volume 2: Boiling Using Enhanced Surfaces, Plate Heat Exchangers and Two-Phase Devices. Chapter 4. chapter Chapter 4. (pp. 145-215). World Scientific Publishing. doi:https : //doi.org/10.1142/9789814623285_0011.

Vist, S., \& Pettersen, J. (2004). Two-phase flow distribution in compact heat exchanger manifolds. Experimental Thermal and Fluid Science, 28, 209-215. doi:10.1016/S0894-1777(03)00041-4.

Yan, Y.-Y., Lio, H.-C., \& Lin, T.-F. (1999). Condensation heat transfer and pressure drop of refrigerant R-134a in a plate heat exchanger. International Journal of Heat and Mass Transfer, 42, 993-1006. doi:10.1016/S0017-9310(98)00217-8.

Zhang, J., Kærn, M. R., Ommen, T., Elmegaard, B., \& Haglind, F. (2019). Condensation heat transfer and pressure drop characteristics of $\mathrm{R} 134 \mathrm{a}, \mathrm{R} 1234 \mathrm{ze}(\mathrm{E}), \mathrm{R} 245 \mathrm{fa}$ and R1233zd(E) in a plate heat exchanger. International Journal of Heat and Mass Transfer, 128, $136-149$. doi:10.1016/j.ijheatmasstransfer.2018.08.124.

Zühlsdorf, B., Jensen, J. K., \& Elmegaard, B. (2019). Heat pump working fluid selection - Economic and thermodynamic comparison of criteria and boundary conditions. International Journal of Refrigeration, 98, 500-513. URL: https://linkinghub.elsevier.com/retrieve/pii/ S0140700718304870. doi:10.1016/j.ijrefrig.2018.11.034.

Zühlsdorf, B., Kjær Jensen, J., Cignitti, S., Madsen, C., \& Elmegaard, B. (2018a). Analysis of temperature glide matching of heat pumps with zeotropic working fluid mixtures for different temperature glides. Energy, 153, 650-660. doi:10.1016/j.energy .2018.04.048.

Zühlsdorf, B., Meesenburg, W., Ommen, T., Thorsen, J., Brix Markussen, W., \& Elmegaard, B. (2018b). Improving the performance of booster heat pumps using zeotropic mixtures. Energy, 154, 390-402. doi:10.1016/j .energy .2018.04.137. 